NBER WORKING PAPER SERIES

\title{
THE EFFECTS OF TRADITIONAL CIGARETTE AND E-CIGARETTE TAXES ON ADULT TOBACCO PRODUCT USE
}

\author{
Michael F. Pesko \\ Charles J. Courtemanche \\ Johanna Catherine Maclean \\ Working Paper 26017 \\ http://www.nber.org/papers/w26017 \\ NATIONAL BUREAU OF ECONOMIC RESEARCH \\ 1050 Massachusetts Avenue \\ Cambridge, MA 02138 \\ June 2019
}

Research reported in this publication was supported by the National Institute on Drug Abuse of the National Institutes of Health under Award Number R01DA045016 (PI: Michael Pesko). The research in this paper was conducted while the authors were Special Sworn Status researchers of the U.S. Census Bureau at the Atlanta Research Data Center. Research results and conclusions expressed are those of the authors and do not necessarily reflect the views of the Census Bureau, the National Center for Health Statistics, or the National Bureau of Economic Research. The results have been screened to ensure that no confidential data are revealed.

NBER working papers are circulated for discussion and comment purposes. They have not been peer-reviewed or been subject to the review by the NBER Board of Directors that accompanies official NBER publications.

(C) 2019 by Michael F. Pesko, Charles J. Courtemanche, and Johanna Catherine Maclean. All rights reserved. Short sections of text, not to exceed two paragraphs, may be quoted without explicit permission provided that full credit, including $\odot$ notice, is given to the source. 
The Effects of Traditional Cigarette and E-Cigarette Taxes on Adult Tobacco Product Use Michael F. Pesko, Charles J. Courtemanche, and Johanna Catherine Maclean

NBER Working Paper No. 26017

June 2019

JEL No. H2,I12,I18

\section{ABSTRACT}

We study the effects of traditional cigarette tax rate changes and e-cigarette tax adoption on use of these products among U.S. adults. Data are drawn from the Behavioral Risk Factor Surveillance System and National Health Interview Survey data over the period 2011 to 2017. Using a differences-in-differences model, we find that higher traditional cigarette taxes reduce adult traditional cigarette use and increase adult e-cigarette use, suggesting that the products are economic substitutes. E-cigarette tax adoption reduces e-cigarette use, with some heterogeneity across groups, and dilutes the own-tax responsiveness of traditional cigarettes.

Michael F. Pesko

Department of Economics

Andrew Young School of Policy Studies

PO Box 3992

Atlanta, GA 30302-3992

Georgia

mpesko@gsu.edu

Charles J. Courtemanche

Department of Economics

Gatton College of Business and Economics

University of Kentucky

Lexington, KY 40506-0034

and NBER

courtemanche@uky.edu
Johanna Catherine Maclean

Department of Economics

Temple University

Ritter Annex 869

Philadelphia, PA 19122

and NBER

catherine.maclean@temple.edu 


\section{Introduction}

As of 2017, 34.4 million adults (14.0\%) in the United States smoked traditional cigarettes and 6.9 million (2.8\%) used electronic cigarettes ('e-cigarettes'), which include electronic cigarettes and other 'vaping' (i.e., using an e-cigarette ${ }^{1}$ ) devices delivering nicotine (Wang et al. 2018). ${ }^{2}$ E-cigarettes may represent a healthier alternative to traditional cigarettes for smokers who cannot quit, by delivering nicotine (the addictive ingredient in tobacco products) without carcinogens and other toxicants found in traditional cigarettes. The U.S. Surgeon General has concluded that, while e-cigarettes are not harmless, these products contain fewer toxicants than traditional cigarettes (U.S. Department of Health and Human Services 2016).

The potential substitutability of traditional cigarettes and e-cigarettes presents a unique challenge to policymakers. On one hand, taxing and restricting access to e-cigarettes may help to reduce overall nicotine intake within the population. On the other hand, such measures may be detrimental to the health of those who smoke by discouraging them from switching to a less harmful source of nicotine (i.e., e-cigarettes) or using e-cigarettes as a cessation device (Hajek et al. 2019). Localities within the U.S. have taken a variety of approaches toward e-cigarette regulation. Early regulations focused on youth access and curtailing use in some public places. More recent regulations include taxes. As of the end of 2018 all but two states have prohibited youth from purchasing e-cigarettes, ${ }^{3} 15$ states have banned the use of e-cigarettes in some public

\footnotetext{
${ }^{1}$ We note that individuals can vape products besides e-cigarettes, but we refer to the act of vaping as exclusive to ecigarette use throughout the paper. We also refer to the act of smoking as exclusive to traditional cigarette use.

${ }^{2}$ E-cigarettes are also referred to as e-cigs, vapes, e-hookahs, vape pens, electronic nicotine delivery systems, and ENDS. There are three types of e-cigarettes: disposable single use products, kits that include a rechargeable device and cartridges containing liquid nicotine, and tank or mod systems used to vaporize liquid nicotine. In this paper, we follow the U.S. Surgeon General's convention in referring to all of these products as e-cigarettes (U.S. Department of Health and Human Services 2016). While most vaping devices include nicotine, we note that some vaping products do not include this ingredient.

${ }^{3}$ Regardless of state law, we note that the Food and Drug Administration's 2016 Deeming Rule established a federal minimum legal sales age of 18 in that year.
} 
places, and nine states have passed e-cigarette excise taxes (Centers for Disease Control and Prevention 2019).

In this study, we leverage cross-state over-time variation in traditional cigarette excise tax rate increases in 18 states that occurred between 2011 and 2017, as well as the implementation of e-cigarette taxes in eight states and two counties, to examine own- and cross-product tax responsiveness. We utilize two national large-scale health survey data sources - the Behavioral Risk Factor Surveillance System and National Health Interview Survey - that include detailed information on both smoking and vaping. We have several key findings. First, traditional cigarette taxes reduce smoking among adults over the period of 2011 to 2017. Second, traditional cigarette taxes increase e-cigarette use among adults, suggesting that the products are economic substitutes. Third, we find some evidence that e-cigarette taxes reduce e-cigarette use, particularly for males. Fourth, the introduction of an e-cigarette tax appears to reduce traditional cigarette own tax-elasticity. This could be because increasing the price of e-cigarettes disincentivizes smokers from trying to quit by using e-cigarettes as a smoking cessation device or transitioning to e-cigarettes as a source of nicotine, which are less harmful, when faced with a traditional cigarette tax rate increase. This finding implies that policymakers attempting to develop an overall tobacco control strategy that involves targeting both traditional cigarettes and e-cigarettes should carefully consider spillovers from one policy to another.

The paper proceeds as follows. Section 2 offers a review of the related literature. Data and variables are described in Section 3, and our methods are discussed in Section 4. Results are reported in Section 5. Finally, Section 6 concludes. 


\section{Related literature}

Our paper builds on the existing bodies of work on the own- and cross-price elasticities of traditional cigarettes and e-cigarettes among U.S. adults. ${ }^{4}$ Below we discuss the existing literature on these topics as well as our specific contributions.

\subsection{Own-price elasticity of traditional cigarettes}

A voluminous economics literature estimates the price elasticity of traditional cigarettes across various countries and time periods. Chaloupka and Warner (2000) review studies prior to 2000, concluding that smoking is responsive to price but relatively inelastic, with most estimated price elasticities of total demand falling in the -0.3 to -0.5 range for adults. A more recent review by the Community Preventive Services Task Force (2014) estimates a traditional cigarette total demand price elasticity of -0.37 for adults, which is approximately equally split by effects on the extensive and intensive smoking margins.

The endogeneity of traditional cigarette prices is a potential concern with these estimates, as prices are determined by changes in demand and supply factors, which could lead to omitted variable bias in regression coefficient estimates and associated elasticity calculations (Gruber and Köszegi 2001, Gruber and Frakes 2006). A large number of more recent economics studies use traditional cigarette taxes rather than prices to reduce these endogeneity concerns. ${ }^{5}$ In 2018 , state taxes represented $23 \%$ of the weighted retail price for traditional cigarettes (Orzechowski and Walker 2018), suggesting that an adult price elasticity of demand of -0.40 converts to a statelevel tax elasticity of demand of approximately -0.10 .

\footnotetext{
4 There is also a literature on the effects of various e-cigarette policies, particularly minimum age laws, on youth smoking (Dave, Feng, and Pesko 2019, Friedman 2015, Pesko and Currie 2019, Pesko, Hughes, and Faisal 2016). ${ }^{5}$ While tax rates are not as directly determined by demand as prices, they are nonetheless established within the state’s political economy and thus not purely exogenous (Besley and Case 2000).
} 
Our contribution to the literature on the own-price elasticity of demand for traditional cigarettes is to calculate an adult smoking participation tax elasticity during the period of time in which e-cigarettes were widely available. Given this objective, benchmarking adult traditional cigarette tax responsiveness for comparison with our findings is important. ${ }^{6}$ We identify several studies calculating traditional cigarette tax rate responsiveness for adults using nationally representative U.S. data just prior to the wide availability of e-cigarettes. We contend that these studies are the most relevant to our own work while acknowledging that they do not reflect the universe of studies estimating traditional cigarette demand equations.

Cotti, Nesson, and Tefft (2016) use household scanner data from 2004 to 2012 to calculate a tax elasticity of -0.16 . Similarly, Nesson (2017) finds an elasticity of -0.15 using the 1988 to 2012 National Health and Nutrition Examination Surveys, Bishop (2018) documents an elasticity of -0.18 using 1999 to 2012 Behavioral Risk Factor Surveillance System data, and Callison and Kaestner (2014) estimate an elasticity range from -0.06 to -0.03 using data from the 1995 to 2007 Current Population Survey Tobacco Use Supplements. By examining more recent data, we explore whether the introduction of e-cigarettes into U.S. tobacco product markets may have altered traditional cigarette tax responsiveness by providing smokers with a popular smoking cessation product. The availability of a close substitute lowers the disutility from quitting smoking, perhaps enabling some smokers to quit smoking or switch to e-cigarettes as a nicotine source as cigarette taxes rise when they would not have been able to do so otherwise.

\footnotetext{
${ }^{6}$ Though our focus here is on prime age adults, we note that there is also a literature using quasi-experimental methods to estimate the tax elasticity of cigarettes among youth (DeCicca, Kenkel, and Mathios 2002, Carpenter and Cook 2008, Hansen, Sabia, and Rees 2017, Courtemanche and Feng 2018) and older adults (DeCicca and McLeod 2008, Maclean, Kessler, and Kenkel 2016).
} 


\subsection{Own-price elasticity of e-cigarettes, and cross-price elasticity between traditional cigarettes} and e-cigarettes

Several recent studies estimate the own-price elasticity of e-cigarettes along with the cross-price elasticity between traditional cigarettes and e-cigarettes. To the best of our knowledge, all studies use e-cigarette prices generated from retail scanner data; that is, researchers construct aggregated, area-level price measures based on prices that retailers in that area scan at purchase. ${ }^{7}$ As we discuss later in the manuscript, localities in the U.S. have only recently implemented e-cigarette taxes, thus earlier studies were not able to exploit this source of plausibly exogenous variation and instead relied on prices, which are likely vulnerable to similar endogeneity concerns noted by Gruber and Köszegi (2001) and Gruber and Frakes (2006) in the context of traditional cigarette prices.

Three studies evaluate the effect of these e-cigarette prices on traditional cigarette and ecigarettes sales. Huang et al. (2018) use data from 2007 to 2014 to estimate e-cigarette ownprice elasticities for rechargeable e-cigarettes of -1.4 and for disposable e-cigarettes of -1.6. Zheng et al. (2017) use data from 2009 to 2013 and document an e-cigarette own-price elasticity of demand of -2.1, a cross-price elasticity of traditional cigarette prices on e-cigarettes sales of 1.9, and a cross-price elasticity of e-cigarette prices on traditional cigarette sales of 0.004 . Stoklosa, Drope, and Chaloupka (2016) use European data from 2011 to 2014 to estimate an ecigarette own-price elasticity of demand of -0.8 and a cross-price elasticity of traditional cigarette prices on e-cigarette sales of 4.6.

Survey data has also been used in four studies to estimate the effect of e-cigarette prices on e-cigarette use. Saffer et al. (2018) use data on adults from the 2014 to 2015 Tobacco Use

\footnotetext{
${ }^{7}$ These prices include excise taxes but do not include sales taxes.
} 
Supplement of the Current Population Survey to estimate an e-cigarette price elasticity of vaping participation of -1.2. Pesko et al. (2018) use two years of the Monitoring the Future Survey data of middle and high school students and find a -1.8 own price elasticity of days vaping. Pesko and Warman (2017) use National Youth Tobacco Survey (NYTS) data from 2011 to 2015 to show that higher e-cigarette cartridge (the fixed component of a rechargeable e-cigarette) prices reduce youth e-cigarette use and increase current traditional cigarette consumption (substitution), especially for males and for older teenagers. Finally, Cantrell et al. (2019) use national longitudinal cohort data on a sample of 15 to 21 year olds from 2014 to 2016 and find no effect of e-cigarette prices, but a cross-cigarette-price elasticity of 0.9.

Discrete choice experiments (DCE) have also been applied to estimate priceresponsiveness of traditional cigarettes and e-cigarettes. DCEs are a stated preference method in which respondents are presented with hypothetical purchasing decisions when product attributes such as prices are varied. Marti et al. (2019), for example, use a sample of adult smokers who are asked to choose between traditional cigarettes and e-cigarettes when price, relative health of e-cigarettes, effectiveness of e-cigarettes as a smoking cessation aid, and coverage of smoking bans in public places are varied. While the probability of selecting an e-cigarette declines as its hypothetical price increases, health reasons appear to be more important than prices for adult smokers' e-cigarette choices. Another recent study suggests more of a role of price in the choice of traditional cigarettes and e-cigarettes (Pesko et al. 2016), with an estimated e-cigarette ownprice elasticity among current adult smokers of 1.8 .

One study explores the effects of traditional cigarette taxes on adult e-cigarette use. Cotti, Nesson, and Tefft (2018) use Nielson household scanner data to show that traditional cigarette tax increases lead to a decline in purchases of both products. This finding implies that 
the products are economic complements, which contrasts the results from the majority of studies discussed above which suggest substitutability across the products.

We contribute to the literature on the own-price elasticity of e-cigarettes by providing, to the best of our knowledge, the first exploration of the effect of e-cigarette taxes - rather than prices - on e-cigarette use. Our study also makes three distinct contributions to the literature on cross-price effects. First, we provide the first analysis of the effect of e-cigarette taxes (rather than prices) on adult smoking. Second, we use survey data to examine the impact of cigarette taxes (rather than prices) on adult e-cigarette use.

Finally, we investigate the potential interactive effect of traditional cigarette and ecigarette taxes, which has not been explored. The intuition is similar to that discussed above regarding the possibility that the widespread availability of e-cigarettes may have altered traditional cigarette own-tax responsiveness. Increasing the price of e-cigarettes implicitly reduces their availability, ${ }^{8}$ which could inhibit some smokers from quitting or switching to the less harmful product as a source of nicotine as traditional cigarette taxes rise. This question is interesting from both an economics perspective and from a practical standpoint. From an economics perspective, this question explores whether price elasticities are potentially a function of the prices of related goods. Additionally, policymakers often adopt both traditional cigarette and e-cigarette regulations as part of an overall tobacco control strategy (Maclean et al. 2018). If these policies have interactive effects, then policymakers may wish to consider how policies operate jointly when selecting the optimal set of regulations for their jurisdiction. Put

\footnotetext{
${ }^{8}$ Through standard price effects: when the price increases the quantity demanded should decrease. We note that there are other non-price pathways from taxes to changes in tobacco product use. For instance, taxes may signal to consumers that the taxed product is unsafe. This phenomenon has been documented in other health behavior contexts, for example soda taxes. See an excellent discussion of this issue by Gostin (2017). We are not able to distinguish between these alternative mechanisms. However, at the market level both predict that consumption should decline following a tax hike.
} 
differently, if taxing both products enhances the effectiveness of either tax, then policymakers should consider developing tobacco control strategies that incorporate both policies. On the other hand, if taxing one product mutes the effectiveness of the alternative tax, then policymakers may wish to consider adopting just one tax to maximize the social objective (e.g., reducing smoking within the population).

\section{Data}

We use data for the period 2011 to 2017 from the Behavioral Risk Factor Surveillance System (BRFSS) and the National Health Interview Survey (NHIS). ${ }^{9}$ These data sources are used by the U.S. federal government to track health behaviors such as vaping and smoking, and are commonly used by health economists (Barbaresco, Courtemanche, and Qi 2015, Miller and Wherry 2017, Horn, Maclean, and Strain 2017, Pesko 2014). We use geocoded versions of the BRFSS and NHIS available through federal statistical research data centers. Thus, we have access to granular geographic information not available in the public use files which allows us to accurately study sub-state taxes.

We combine these two data sources to maximize data on e-cigarette use, which have only recently been added to national surveys. We note that combing data sets in this manner is not uncommon within economics (Maclean, Tello-Trillo, and Webber 2019, Webber 2016, Farber et al. 2018, Altonji, Kahn, and Speer 2016, Miller 2012). The BRFSS surveys over 400,000 adults annually and the NHIS surveys approximately 33,000 adults annually as part of its adult sample, which is the module in which e-cigarette information is queried. Traditional cigarette use and e-

\footnotetext{
${ }^{9}$ We begin our study period in 2011 due to a change in the BRFSS survey frame. Prior to 2011, the BRFSS, which is a telephone survey, only conducted surveys on landlines. Beginning in 2011, cellphones were added to the survey frame to better capture a population that represented the U.S. This change lead to a compositional shift in survey respondents and thus we follow CDC recommendations and do not combine pre- and post-2011 data. In addition, the focus on relatively recent years also enables us to isolate the period in which e-cigarettes were widely available in U.S. tobacco product markets, which is our main contribution to the traditional cigarette tax elasticity literature.
} 
cigarette questions are available in both data sources. To measure traditional cigarette use, respondents are first asked if they have smoked at least 100 traditional cigarettes in their lifetime, and if so, if they now smoke every day, some days, or not at all. E-cigarette questions were added to the BRFSS in 2016 and were added to the NHIS in 2014. In both data sources, respondents are asked if they have ever used e-cigarettes and if so, if they now use e-cigarettes every day, some days, or not at all.

We make two sample restrictions. First, we exclude individuals ages 18 to 20 to avoid confounding from Tobacco 21 laws that were being enacted during this time period (Winickoff, Gottlieb, and Mello 2014). Second, we drop the state of Alaska because of limited geographical information, even in the restricted versions of these files that we use; full details are available on request. Relatedly, the years of data differ across our smoking and vaping outcomes based on data availability in the BRFSS and NHIS. We use 2011 to 2017 for our smoking outcomes in both data sources. For our vaping outcomes, we use 2014 to 2017 in the NHIS and 2016 to 2017 in the BRFSS; these are the years for which we have vaping information.

We create harmonized demographic variables across the two data sources, which we include in our empirical models. More specifically, we include the following individual-level control variables in our regressions: sex (female and male), education (less than high school, high school or graduate education development [GED], some college, and college or more, and missing), race (white, black, Asian, Native American/Alaskan Native, other, and missing), marital status (married, divorced, widowed, separated, never married, and missing), age, health insurance status (insured, not insured, and missing), employment (currently employed, not currently employed, and missing), and income. 
While most variables in the data sources are very similar, an exception is income information. In particular, BRFSS collects household income while NHIS collects personal income. We account for this difference in the following manner. Separately for each data source, we convert the categories into a pseudo-continuous variable and then impute missing values using state-year means. We control for the differences in income across data source by interacting the harmonized income variable with an indicator for data source. We also control for separate indicators for the top income category, the amounts of which vary across the data sources. Our results are insensitive to including/excluding income as a control variable; regression results without income as a control are not shown but are available on request. We obtain dates of state cigarette excise tax changes from the Centers for Disease Control and Prevention (2019). We also obtain sub-state traditional cigarette excise tax changes affecting localities with 100,000 people or more using proprietary data obtained from the American Non-Smokers Rights Foundation. Effective dates of e-cigarette taxes are collected from the CDC State System (2019) and the Vapor Products Tax Data Center (2018).

Appendix Table 1 provides a list of the localities that changed their traditional cigarette tax rate between 2011 and 2017, and Appendix Table 2 lists localities that levied an e-cigarette tax by the end of 2017. Figures 1 and 2 depict these taxes graphically, and Figures 3 and 4 report the number of traditional cigarette changes and e-cigarette tax adoptions in each year of our study period. While there is some clustering of higher traditional cigarette taxes in the West and the Northeast, we do have reasonable variation in these taxes across the country. In terms of ecigarette tax adoption, there is no obvious clustering in specific geographic areas and we observe adopting localities in all four regions of the country. Traditional cigarette tax changes are 
relatively homogenous across years while e-cigarette tax adoptions are more concentrated in the latter half of the study period.

While traditional cigarette excise taxes are standardized across localities (i.e., a dollar value per pack of 20 traditional cigarettes), localities levy e-cigarette taxes in different ways. Of these 11 localities levying an e-cigarette tax through by the end of 2017, five use an ad valorem tax on the wholesaler, five use an excise tax, and one uses a sales tax. ${ }^{10}$ Given the difficulty of comparing the magnitudes of these different types of taxes, in our regression models we simply use an indicator for whether or not a locality has levied an e-cigarette tax. We note this variable construction as a limitation of the study.

We also control for several time-varying area-level factors in our regression models: county-level percent of the population covered by indoor vaping restrictions in bars, restaurants, and private workplaces (Cooper and Pesko 2017); state-level bans on smoking in restaurants, private workplaces, or bars (separate indicators) (Centers for Disease Control and Prevention 2019); beer taxes (National Institute on Alcohol Abuse and Alcoholism 2019); medical marijuana laws (Sabia and Nguyen 2018); marijuana decriminalization laws (Pacula, Chriqui, and King 2003); ${ }^{11}$ prescription drug monitoring programs (Ali et al. 2017); Affordable Care Act Medicaid expansion status (Maclean, Pesko, and Hill 2019); and unemployment rates (University of Kentucky Center for Poverty Research 2019). All monetary values are Consumer Price Index (CPI)-adjusted to 2010 dollars. We link area-level variables to the combined BRFSS and NHIS data set using year/quarter and county/state information available in both data sources.

\footnotetext{
${ }^{10}$ Both Chicago and Cook County have adopted an e-cigarette tax. We assume that the earlier tax in Chicago affects all of Cook County, since we cannot separate Chicago residents from the rest of Cook County in our data.

${ }^{11}$ We thank Rosalie Pacula for sharing an updated version of the marijuana decriminalization variable with us.
} 
Descriptive statistics for both data sources combined are presented in Table 1, and separately for the BRFSS and the NHIS in Appendix Tables 3 and 4 respectively. For each table, variable means are presented separately for all respondents, respondents residing in localities that have levied an e-cigarette tax by the end of 2017, and respondents residing in localities that have not levied such a tax by the end of 2017. Overall, $15.8 \%$ of respondents use traditional cigarettes, $11.4 \%$ of respondents use traditional cigarettes daily, $3.1 \%$ of respondents currently use e-cigarettes, and 1.1\% currently use e-cigarettes every day. The average traditional cigarette excise tax rate is $\$ 1.45$ per pack and the share of respondents residing in a locality that had adopted an e-cigarette tax by 2017 is $6.3 \%$.

Among respondents residing in localities adopting an e-cigarette tax, current traditional cigarette use is 0.1 percentage points ('ppts') higher and current e-cigarette use is 0.2 ppts lower than use rates among respondents residing in localities not adopting such a tax. Localities adopting e-cigarettes taxes are more racially/ethnically diverse, younger, and lower income that non-adopting localities. The localities adopting e-cigarette taxes also have lower traditional cigarette and beer taxes and more restrictions on marijuana use (both recreational and medical) While there are some differences in policies and demographics across groups, they do not appear to be substantial. Moreover, we control for these differences in all regression models.

\section{Methods}

We estimate differences-in-difference (DD) regression-style models. Specifically, we estimate the regression model outlined in Equation (1):

$$
Y_{i, c, s, t}=a+\beta \operatorname{Ttax}_{c, s, t}+\partial \operatorname{Etax}_{c, s, t}+Z_{c, s, t} \emptyset+X_{i, c, s, t} \theta+\gamma_{c, s}+\tau_{t}+\varepsilon_{i, c, s, t}
$$

$i$ indexes an individual interviewed in year-quarter $t$, who resides in county $c$ of state $s . Y_{i, c, s, t}$ is an indicator for whether the individual smokes, smokes every day, vapes, or vapes every day. 
$Z_{c, s, t}$ includes the time-varying state- or county-level policies. $X_{i, c, s, t}$ includes demographics, an indicator for whether the observation was surveyed in the BRFSS or the NHIS, and an interaction between data source and income. We control for county fixed effects $\left(\mathrm{\gamma}_{c, s}\right)$, which mitigate potential bias from time-invariant, county-specific factors. Note that county fixed effects incorporate state fixed effects. Including these fixed effects allows us to leverage within locality (county or state) variation in tobacco and e-cigarette taxes for identification of treatment effects. We also control for year-quarter fixed effects $\left(\tau_{t}\right)$ that account for time varying factors affecting the nation as a whole, such as the general decline in smoking and sharp increase in the popularity of e-cigarettes that occurred over our study period.

$\beta$ and $\partial$ are our primary coefficients of interest and capture the effect of tobacco and ecigarette taxes on our outcomes. We expect own-taxes will reduce current use of these products, but the cross-tax effects are a-priori ambiguous. Cross-tax effects will be positive if the goods are substitutes, negative if the goods are complements, and zero if the goods are unrelated. As discussed in Section 2, the literature has not yet reached consensus on whether these products are complements or substitutes among adults, although most studies to date suggest substitution.

A necessary assumption for the DD model to recover causal estimates is that the treatment (i.e., localities changing traditional cigarette taxes or adopting e-cigarette taxes) and the comparison (i.e., localities not changing traditional cigarette taxes or adopting e-cigarette taxes) groups would have followed the same trend in the post-treatment period had the treatment localities not been treated (i.e., not changing the traditional cigarette tax or adopting an ecigarette tax). This assumption is referred to as 'parallel trends.' Clearly this assumption is untestable as treated localities were treated in the post-period, preventing us from observing counterfactual trends. Instead, we follow the economics literature and provide suggestive 
evidence on whether the parallel trends assumption is satisfied in our data by modifying

Equation (1) to conduct an event study (Autor 2003).

To implement the event study, we replace the traditional cigarette tax rate with an indicator variable for if the traditional cigarette tax increased by $\$ 0.50$ or more at any point during the study period following; we refer to such a change as a 'large' traditional cigarette tax increase (Callison and Kaestner 2014). ${ }^{12}$ For both the large traditional cigarette tax increase and e-cigarette tax adoption variables, we create mutually exclusive policy lead variables for $>2$ years in advance and 2 to $>1$ year in advance of the tax. We include one lag indicator for the post period. The omitted category is the year prior to the tax adopting ( 1 to $>0$ years). ${ }^{13}$ We code all non-adopting localities as zero for all event-time indicators (Lovenheim 2009). All other variables are as defined in Equation (1). If the policy lead coefficients are small in magnitude and statistically indistinguishable from zero, this pattern of results suggests that there were no changes in smoking or vaping prior to adoption of the policy. Such results can be interpreted as providing suggestive evidence that a covariate-adjusted version of the parallel trends assumption is met and that our DD models can recover causal estimates.

To further assess the validity of our design, we follow Pei, Pischke, and Schwandt (2018) and test for balance across treatment and comparison groups by separately regressing traditional cigarette and e-cigarette taxes on all covariates in Equation (1); we aggregate demographic variables to the county-level. If the covariates are uncorrelated with our tax variables, we can

\footnotetext{
${ }^{12}$ Eleven states passed a cigarette excise tax increase of $\geq \$ 0.50$ during the study period and no states passed more than two such increases. Due to local taxes, both Cook County and Philadelphia County had more than one $\$ 0.50$ excise tax increase, in which case we study trends prior to the first large increase.

${ }^{13}$ We exclude three states (Illinois, Massachusetts, and Minnesota) that passed large cigarette tax increases between 2011 and 2013 to ensure that our policy lead coefficients are not reflecting any compositional effects in the population of tobacco product users. This exclusion also removes the only locality passing an early e-cigarette tax and is therefore a treated control (Minnesota passed an e-cigarette tax in 2010, prior to our study period).
} 
interpret this finding as providing suggestive evidence that treatment and comparison groups are conditionally balanced and that our data satisfy the conditional independence assumption (CIA).

We also test whether the adoption of an e-cigarette tax alters traditional cigarette tax responsiveness. The relatively new availability of e-cigarettes offers smokers another option for smoking cessation and recent clinical trial evidence suggests that e-cigarettes are an effective option for some smokers (Hajek et al. 2019). Higher traditional cigarette taxes could therefore result in a steeper decline in smoking if people that would otherwise not quit in the absence of ecigarettes now do so, implying that traditional cigarette tax responsiveness may be larger in more recent years as e-cigarettes have become more widely available and the potential of these products as smoking cessation devices is better understood. On the other hand, e-cigarette taxes could reduce the ability of individuals to purchase these products, therefore restricting smoking cessation opportunities, leading to a smaller traditional cigarette own-tax elasticity. To explore this hypothesis, we estimate a version of Equation (1) that includes an interaction between the traditional cigarette tax rate and e-cigarette tax adoption variables. As documented in Appendix Tables 1 and 2, most of the localities adopting an e-cigarette tax also implemented changes to their traditional cigarette tax rate during the study period, providing useful variation to explore the effect of traditional cigarette taxes in localities with and without an e-cigarette tax.

We estimate unweighted linear probability models. We cluster standard errors at the level of the state (Bertrand, Duflo, and Mullainathan 2004); we use both county- and state-level variation in taxes and thus the most appropriate level at which to cluster is unclear. In unreported analyses, we have clustered at the level of the county and results are similar. 


\section{Results}

\subsection{Effects of traditional cigarette and e-cigarette taxes on adult tobacco product use}

Our main DD results are reported in Table 2 for all individuals in both data sources. We also report results generated in the BFRSS only (Table 3) and the NHIS only (Table 4). A \$1 increase in the traditional cigarette tax reduces current traditional cigarette use by 0.3 ppts and everyday traditional cigarette use by 0.4 ppts, which represents a $1.9 \%$ and $3.5 \%$ reduction compared to the smoking rates in the sample. Given a mean traditional cigarette state excise tax rate of $\$ 1.45$, these estimates imply a modest own-tax elasticity of demand of -0.03 for current smoking and -0.05 for daily smoking. Our modest tax elasticity estimates are in line with Callison and Kaestner (2014) who report elasticities of -0.03 to -0.06 . We note, however, that our elasticities are lower than other recent estimates of -0.15 to -0.18 (Cotti, Nesson, and Tefft 2016, Nesson 2017, Bishop 2018). In sum, we do not find evidence that traditional cigarette tax responsiveness is greater as e-cigarettes have become more available.

A $\$ 1$ traditional cigarette excise tax increase also increases current vaping by 0.3 ppts ( $9.7 \%$ of the mean) and everyday vaping by 0.1 ppts ( $9.1 \%$ of the mean), suggesting that the two products are economic substitutes. We do not find any statistically significant evidence that ecigarette taxes influence traditional cigarette use, however. These findings depart from previous work using scanner data (see Section 2). We suspect that we are potentially under-powered to detect these effects. For instance, five times more people report current smoking than current vaping in our data, which implies that the vaping market is much smaller. All else equal, the researcher is more likely to detect statistically significant effects of a tax change when the market is larger, ${ }^{14}$ which could explain why we were able to measure statistically significant increases in

\footnotetext{
${ }^{14}$ As an illustrative example, imagine a hypothetical market in which $50 \%$ of individuals purchase product A and $10 \%$ of individuals purchase closely related product B. Further, the cross-tax elasticity of demand for both products
} 
the effect of cigarette taxes on e-cigarette use but not the reverse. We suspect that, over time given current trends in e-cigarette use, the market size will increase and future studies will provide more insight on this question. Nonetheless, given the regulatory action on the part of numerous localities across the U.S., providing an early evaluation of e-cigarette taxation effects is important and useful.

Adoption of an e-cigarette tax leads to a 0.2 ppts (6.5\% of the mean) reduction in vaping, but this estimate is not statistically significant. However, in looking strictly at the BRFSS data in Table 3, we find that adoption of an e-cigarette tax reduces current e-cigarette use by 0.3 ppts (9.7\% of the mean) and this estimate is statistically distinguishable from zero. The NHIS data in Table 4 suggests a 0.2 ppt decrease in e-cigarette use (6.5\% of the mean), which is nearly identical in magnitude to what we observe in the BRFSS, although like in our combined sample this estimate is not statistically significant.

While we cannot fully explore why estimates are more precise in the BRFSS than in the combined BRFSS and NHIS or NHIS datasets, one possibility is that the data sources use somewhat different sources of variation. E-cigarette questions were added to BRFSS in 2016 and NHIS in 2014. Later e-cigarette taxes (and changes in these taxes for early adopters, since several early adopters later changed the rate) could plausibly have been more impactful than earlier taxes. Appendix Table 2 provides some suggestive support for this hypothesis. Several tax changes contribute to the identifying variation in the NHIS sample years but not the BRFSS sample years, including those in Washington, DC; Montgomery County, Maryland; Louisiana; and North Carolina. The e-cigarette taxes levied by these early adopters appears smaller than

is 0.1 . A $10 \%$ increase in the taxes of product $A$ would therefore increase consumption of product B by five ppts (50\%), whereas a $10 \%$ increase in the taxes of product B would increase consumption of product A by only one ppt (2\%). Therefore, it is much easier in this illustrative case to detect statistically significant product A cross-tax effects than product B cross-tax effects. 
taxes levied by later adopting localities, in particular the $\$ 0.05$ excise taxes per fluid milliliter in Louisiana and North Carolina is smaller than all subsequently enacted initial excise tax levels.

The results in Table 4 (which rely exclusively on the NHIS) suggests larger effects of taxes on traditional cigarette use. For example, a $\$ 1$ increase in traditional cigarette taxes reduces current traditional cigarette use by 0.8 ppts ( $4.5 \%$ of the mean) and daily traditional cigarette use by 0.7 ppts (5.2\% of the mean). Adoption of an e-cigarette tax increases current traditional cigarette use by 0.4 ppts ( $2.3 \%$ of the mean). While this final result is not statistically significant, the point estimate suggests substitution. However, these taxes have little effect on ecigarette use in the NHIS data.

\subsection{Internal validity of the research design}

In Table 5 we report estimates and associated standard errors for our tobacco and ecigarette use outcomes generated using our event study. The reference period is the year immediately prior to adoption of a large traditional cigarette tax increase and adoption of an ecigarette tax. For both the large traditional cigarette tax and e-cigarette tax adoption leads, coefficient estimates are statistically indistinguishable from zero and small in magnitude. We interpret these null findings to suggest that our data are potentially able to satisfy a covariateadjusted version of the parallel trends assumption.

Compared to the year immediately prior to a large traditional cigarette excise tax adoption, such an increase in this tax reduces everyday traditional cigarette use by 0.3 ppts (2.6\% of the mean) and increases current vaping by 0.4 ppts (12.9\% of the mean). We note that we lose precision for some of our lag estimates (vs. estimates generated in our DD-style model). We attribute the precision loss to the fact that event studies are more data hungry than DD-style models. Reassuringly, the overall pattern of results is comparable across the two specifications. 
We also assess the ability of our data to satisfy the CIA by following Pei, Pischke, and Schwandt (2018) and regressing both taxes on all other right hand side variables. In results not shown, but available on request, we observe that demographics do not predict cigarette tax rates or e-cigarette tax adoption, suggesting that individuals do not migrate in observable ways in response to changes in tobacco taxation. Tobacco control policies and medical marijuana laws do predict the traditional cigarette tax rate. Given that these policies all attempt to regulate addictive substances, the observed correlations may reflect overall strategies adopted by localities to reduce substance use. Under the hypothesis of an overall strategy adopted by a locality, these correlations are potentially not unexpected. In terms of e-cigarette adoption, only the traditional cigarette rate predicts this outcome, which plausibly reflects localities adopting broader tobacco control efforts to reduce nicotine consumption (Maclean et al. 2018). We acknowledge that our data display some evidence of policy imbalance, in particular in terms of regulation of related goods, but we are able to control for all variables in our regression models.

\subsection{Heterogeneity in tax effects on adult tobacco product use}

In Tables 6 to 8, we explore if subgroups differ in responsiveness to these taxes. Given differences in use of these products (Wang et al. 2018) and perceptions regarding their health harms (Glasser et al. 2017), tax responsiveness may also vary. For both men and adults less than 35 years of age, we document similar traditional cigarette tax effects. Among men, a $\$ 1$ increase in the traditional cigarette tax reduces current and daily smoking by 0.6 ppts; $3.4 \%$ and $4.8 \%$ of the respective means. A $\$ 1$ increase in this tax reduces current and daily smoking among adults under 35 years by 0.5 ppts ( $2.3 \%$ of the mean) and 0.6 ppts ( $4.1 \%$ of the mean). This tax hike also increases current and daily vaping among men by 0.5 ppts ( $13.9 \%$ of the mean) and 0.2 ppts (15.4\% of the mean). E-cigarette tax adoption reduces current vaping by 0.5 ppts among men 
which corresponds to $13.9 \%$ of the mean. Women do not appear to change their smoking or vaping patterns following traditional cigarette tax rate changes or e-cigarette tax adoption.

\subsection{Interactions between traditional cigarette and e-cigarette taxes}

In Table 9 and 10, we report results from our interactive model (i.e., interacting the traditional cigarette tax with an indicator for e-cigarette tax adoption). This specification allows us to explore if e-cigarette tax adoption alters traditional cigarette tax responsiveness by reducing the financial incentive to use a popular alternative nicotine product that can be used for smoking cessation purposes (i.e., e-cigarettes). We explore the effect on both current and daily traditional cigarette use, for all respondents and by subgroups defined by sex and age.

The traditional cigarette tax main effect captures traditional cigarette tax responsiveness in the absence of an e-cigarette tax. Summing the traditional cigarette tax coefficient and the interaction coefficient estimates reveals traditional cigarette tax responsiveness in the presence of an e-cigarette tax. If the interaction coefficient estimate is positive, this pattern of results can be interpreted to imply that a traditional cigarette tax hike reduces traditional cigarette use to a lesser degree than if the e-cigarette tax had not been adopted.

For current traditional cigarette use in Table 9, the interaction term is positive for all groups, although only reaching statistical significance for males. For everyday traditional cigarette use in Table 10, the coefficient estimate on the interaction term is statistically significant and positive for all groups. These results collectively suggest that adoption of an ecigarette tax dilutes traditional cigarette tax responsiveness. For example, the ratio of the traditional cigarette tax main effect coefficient estimate to the interaction term coefficient estimate, for daily smoking among all respondents, suggests that e-cigarette tax adoption reduces approximately two-thirds of the effect that traditional cigarette taxes would have on daily 
smoking absent an e-cigarette tax. However, the e-cigarette tax main effect is negative and roughly the same magnitude as the interaction coefficient. This finding suggests that only once the traditional cigarette excise tax exceeds $\$ 1$ does an e-cigarette tax begin to reduce traditional cigarette tax responsiveness.

\section{Discussion}

In this paper, we provide the first evidence on the effects of traditional cigarette taxes on traditional cigarette use and e-cigarette use in a time period when e-cigarettes were widely available in tobacco markets, and the effects of e-cigarette taxes on these outcomes. To do so, we combine data from two large-scale survey datasets, BRFSS and NHIS, and detailed information on state and county traditional cigarette and e-cigarette taxes with a differences-indifferences design. Overall, we observe that, as has been documented in previous studies estimating traditional cigarette demand equations, smoking declines when traditional cigarette tax rates increase. We also find evidence that adults are more likely to use e-cigarettes when traditional cigarette taxes rise, which mirrors evidence from retail sales data using variation in ecigarette prices (Zheng et al. 2017, Stoklosa, Drope, and Chaloupka 2016). We observe some evidence that adoption of an e-cigarette tax reduces vaping, but this finding is somewhat sensitive to sample definition and sub-group. In particular, evidence gleaned from the BRFSS only suggests that e-cigarette use propensity declines post-e-cigarette tax adoption, but not in our combined data set or the NHIS in isolation. Regardless of the data source, we observe that men reduce their e-cigarette use following an e-cigarette tax adoption. Finally, traditional cigarette taxes appear to be less effective - in terms of reducing smoking - when a locality has also adopted an e-cigarette tax. 
The finding that e-cigarette adoption appears to dilute the effectiveness of traditional cigarette taxes, a standard policy lever used to reduce smoking, is important from both an economic and a practical standpoint. We hypothesize that adoption of an e-cigarette tax increases the price of a potential smoking cessation device (Hajek et al. 2019), which dissuades some smokers from attempting to quit or reduce smoking by taking up vaping in response to a traditional cigarette tax increase. Indeed, traditional smoking cessation devices (e.g., Food and Drug Administration-approved nicotine replacement therapies such as Zyban, Chantix, or Nicotrol) are expensive (Maclean, Pesko, and Hill 2019), particularly without insurance, and may not be feasible for smokers, who are on average lower-income (Remler 2004). Moreover, ecigarettes are perceived as effective smoking cessation devices, and more effective than traditional smoking cessation options among some groups of smokers (Glasser et al. 2017, Harrell et al. 2014). Therefore, when the price of e-cigarettes is increased following adopting of a tax, smokers may be less likely to attempt smoking cessation (Saffer et al. 2018) or smoking reduction. Overall, without speaking to specific pathways, this finding suggests that the combination of a traditional cigarette tax hike and e-cigarette tax prevents smokers for either quitting or switching to a less harmful product, both actions would improve smoker health by minimizing exposure to carcinogens and other toxins contained in traditional cigarettes.

From the perspective of the policymaker, understanding policy interactions is important for developing the effective strategies to achieve social goals. Previous economic studies have, for example, documented policy spillovers in the context of Medicaid (Burns and Dague 2017), minimum wages (Page, Spetz, and Millar 2005), workers compensation (McInerney and Simon 2012), and medical marijuana laws (Bradford and Bradford 2018). Failure to consider such potential spillovers can lead to sub-optimal policies. 
We suspect that our focus on (primarily) the extensive margins of traditional cigarette and e-cigarette use likely leads us to understate the tax effects. That is, following a traditional cigarette tax hike or adoption of an e-cigarette tax, some individuals may reduce the quantity demanded on the intensive margin (e.g., number of traditional cigarettes smoked or e-cigarettes vaped per day) but not quit completely. While we do examine daily smoking and vaping, we are unable to fully capture this margin given information available in both data sources.

We note that our findings depart from a seminal and related study by Cotti, Nesson, and Tefft (2018). Whereas we document that traditional cigarettes and e-cigarettes are economic substitutes, Cotti, Nesson, and Tefft (2018) provide evidence of complementarity between the two products. While our data will not allow us to fully explore differences in findings, we can propose potential hypotheses.

First, Cotti, Nesson, and Tefft (2018) use data from 2011 to 2015 and we use data that includes 2016 and 2017, in which nine additional localities increased their traditional cigarette excise taxes; the states passing such taxes are: California, Connecticut, Delaware, Louisiana, Minnesota, Oregon, Pennsylvania, Rhode Island, and West Virginia. The locations passing traditional cigarette taxes in 2016 and 2017 are different from the locations passing such taxes over the period 2011 to 2015. In particular, California is a treatment state in our study because they enacted a cigarette tax increase in April, 2017, but California, a very large state with a historically strong tobacco control program, was a control locality during the time period investigated by Cotti, Nesson, and Tefft (2018).

Second, there are important differences in measures of use captured by the survey data compared to household purchases captured by the scanner data. In the scanner data, Cotti, Nesson, and Tefft (2018) document that 9.5\% of households report purchasing traditional 
cigarettes over the last quarter, compared to $15.8 \%$ that report currently smoking in our survey data. Thus, current smoking is $66 \%$ more common than household purchasing of traditional cigarettes. One potential explanation for this difference is that smokers may cluster in the same households, which would cause household purchasing rates to be smaller than individual use rates. For example, Sterba et al. (2011) surveys partnered smokers who called a quitline; 54.1\% of callers report that their partner also smokes. Another potential explanation is that some individuals may use e-cigarettes without purchasing them (e.g., 'bumming'). Further, in the scanner data, only $0.3 \%$ of households report purchasing e-cigarettes while we estimate a current vaping rate of 3.1\% using survey data. Thus, our vaping use rate is ten times the household purchase rate estimated by Cotti, Nesson, and Tefft (2018) and likely well outside the range that could be explained by clustering of people that vape in the same household. One remaining potential explanation is that individuals may be much more likely to 'bum' e-cigarettes than traditional cigarettes; for example, by sharing a communal vaping device such as a tank system. Therefore, these differences between use measures captured in our data and household purchases captured in retail data may also contribute to differences in our findings.

Our study has limitations. First, because e-cigarette questions have only recently been added to large-scale health surveys, we have limited data on e-cigarette use. Second, while we can measure daily smoking and vaping, we cannot - due to information collected in our data sources - fully examine effects on the extensive margin of tobacco product use. As noted earlier, this data feature likely leads us to understate tax effects. Third, we rely on self-reported traditional cigarette and e-cigarette use which may be measured with some error. Fourth, due to substantial heterogeneity in the manner in which localities have adopted e-cigarette taxes, and no obvious way to standardize these taxes, we include an indicator for a tax rather than a tax rate as 
is common in economic analyses of traditional cigarettes. Finally, we note that our data sources are not representative at the level of treatment for all traditional cigarette tax changes and ecigarette tax adoptions that occurred during our study period. For example, some of the policy changes we leverage occurred at the sub-state level (city or county) and our data sources are not representative at that level, which can lead to empirical issues (Maclean, Tello-Trillo, and Webber 2019). We believe that our ability to combine two large data sources may mitigate this issue, but acknowledge that ideally we would have access to data that is representative at the level of treatment for all included localities.

Our research contributes further evidence from differences-in-differences methods that regulating e-cigarettes have the unintended consequence of raising traditional cigarette use; while neither product is harmless, the clinical literature strongly suggests that e-cigarettes are the less harmful product. With few exceptions (Abouk and Adams 2017, Cotti, Nesson, and Tefft 2018), this finding has been documented for youth (Dave, Feng, and Pesko 2019, Pesko, Hughes, and Faisal 2016, Pesko and Currie 2019, Friedman 2015), pregnant women (Cooper and Pesko 2017, Pesko and Currie 2019), and now for the first time adults. These results suggest caution in regulating e-cigarettes because they may increase smoking of traditional cigarettes. 
Table 1: Summary statistics among respondents in all localities, and localities that did and did not adopt an ecigarette tax by 2017: Combined BRFSS and NHIS data 2011-2017

\begin{tabular}{|c|c|c|c|}
\hline Sample: & $\begin{array}{c}\text { All } \\
\text { localities }\end{array}$ & $\begin{array}{c}\text { Adopting } \\
\text { localities }\end{array}$ & $\begin{array}{c}\text { Non-adopting } \\
\text { localities }\end{array}$ \\
\hline \multicolumn{4}{|l|}{ Outcomes: } \\
\hline Smoking & 0.158 & 0.159 & 0.158 \\
\hline Daily smoking & 0.114 & 0.114 & 0.114 \\
\hline Vaping & 0.031 & 0.029 & 0.031 \\
\hline Daily vaping & 0.011 & 0.010 & 0.011 \\
\hline \multicolumn{4}{|l|}{ Traditional cigarette and e-cigarette taxes } \\
\hline Traditional cigarette tax rate (\$ per pack) & $1.445(0.925)$ & $1.249(0.791)$ & $1.493(0.949)$ \\
\hline E-cigarette tax (any) & 0.063 & 0.320 & 0.000 \\
\hline \multicolumn{4}{|l|}{ Area-level controls } \\
\hline Restaurant smoking ban & 0.684 & 0.643 & 0.694 \\
\hline Private workplace smoking ban & 0.690 & 0.668 & 0.696 \\
\hline Bar smoking ban & 0.573 & 0.569 & 0.574 \\
\hline Indoor vaping restrictions (\% population) & $0.137(0.318)$ & $0.138(0.307)$ & $0.137(0.320)$ \\
\hline Beer tax (\$ per gallon) & $0.236(0.200)$ & $0.170(0.098)$ & $0.253(0.215)$ \\
\hline Medical marijuana law & 0.411 & 0.380 & 0.418 \\
\hline Marijuana decriminalized & 0.333 & 0.241 & 0.356 \\
\hline Prescription drug monitoring program & 0.949 & 0.961 & 0.946 \\
\hline ACA-Medicaid expansion & 0.313 & 0.333 & 0.308 \\
\hline Unemployment rate (\%) & $6.027(2.032)$ & $6.455(2.143)$ & $5.923(1.990)$ \\
\hline \multicolumn{4}{|l|}{ Individual-level controls } \\
\hline Female & 0.587 & 0.574 & 0.590 \\
\hline Male & 0.413 & 0.426 & 0.410 \\
\hline Less than high school & 0.088 & 0.098 & 0.087 \\
\hline High school or GED & 0.279 & 0.261 & 0.283 \\
\hline Some college & 0.273 & 0.265 & 0.275 \\
\hline College degree or more & 0.353 & 0.368 & 0.350 \\
\hline Education missing & 0.006 & 0.007 & 0.006 \\
\hline White & 0.828 & 0.801 & 0.834 \\
\hline African American & 0.093 & 0.111 & 0.089 \\
\hline Asian & 0.022 & 0.039 & 0.018 \\
\hline Native American or Alaskan & 0.019 & 0.015 & 0.020 \\
\hline Other race & 0.022 & 0.022 & 0.022 \\
\hline Race missing & 0.016 & 0.011 & 0.018 \\
\hline Married & 0.540 & 0.533 & 0.542 \\
\hline Divorced & 0.138 & 0.131 & 0.140 \\
\hline Widowed & 0.125 & 0.112 & 0.128 \\
\hline Separated & 0.022 & 0.023 & 0.021 \\
\hline Never married & 0.169 & 0.195 & 0.163 \\
\hline Marital status missing & 0.006 & 0.006 & 0.006 \\
\hline Age (years) & 55.08 (16.69) & $53.52(16.86)$ & $55.46(16.63)$ \\
\hline Uninsured & 0.099 & 0.105 & 0.098 \\
\hline Insured & 0.897 & 0.891 & 0.898 \\
\hline Insurance missing & 0.004 & 0.005 & 0.004 \\
\hline Income (\$; missing values imputed) & $42,975(25,879)$ & $42,564(26,636)$ & $43,075(25,689)$ \\
\hline Unemployed or not in labor force & 0.482 & 0.456 & 0.488 \\
\hline Employed & 0.511 & 0.536 & 0.504 \\
\hline Employment missing & 0.007 & 0.008 & 0.007 \\
\hline Observations & $3,637,821$ & 716,059 & $2,921,762$ \\
\hline
\end{tabular}

Notes: Data are unweighted. The unit of observation is an individual in a county in a year. Standard deviations for continuous variables are reported in parentheses. 
Table 2: Effects of traditional cigarette and e-cigarette taxes on smoking and vaping outcomes among adults using a differences-in-differences-style model: Combined BRFSS and NHIS data 2011-2017

\begin{tabular}{lcccc}
\hline Outcome: & Smoking & Daily smoking & Vaping & Daily vaping \\
\hline Traditional cigarette rate (\$ per 20 & $-0.003^{* * *}$ & $-0.004^{* * *}$ & $0.003^{* *}$ & $0.001^{* * *}$ \\
unit pack) & {$[-0.006,-0.001]$} & {$[-0.006,-0.002]$} & {$[0.001,0.006]$} & {$[0.000,0.002]$} \\
E-cigarette tax (any) & 0.000 & -0.001 & -0.002 & -0.000 \\
& {$[-0.003,0.004]$} & {$[-0.004,0.002]$} & {$[-0.005,0.001]$} & {$[-0.002,0.001]$} \\
\hline Observations & $3,263,753$ & $3,261,037$ & 969,659 & 969,350 \\
Proportion of outcome variable & 0.158 & 0.114 & 0.031 & 0.011 \\
Number of clusters & 50 & 50 & 50 & 50 \\
\hline Notes: The unit of observation is an individual in a county in a year. Data are unweighted. Models estimated with a \\
linear probability model and control for area-level and individual-level variables reported in Table 1, county fixed- \\
effects, and quarter-by-year fixed effects. 95\% confidence intervals account for within state correlations and are \\
reported in square brackets. \\
***; **; and * = statistically different from zero at the 1\%; 5\%; and 10\% level.
\end{tabular}


Table 3: Effects of traditional cigarette and e-cigarette taxes on smoking and vaping outcomes among adults using a differences-in-differences-style model: BRFSS data 2011-2017

\begin{tabular}{lcccc}
\hline \hline Outcome: & Smoking & Daily smoking & Vaping & Daily vaping \\
\hline Traditional cigarette rate (\$ per 20 & $-0.003^{* *}$ & $-0.003^{* * *}$ & $0.004^{* * *}$ & $0.001^{* *}$ \\
unit pack) & {$[-0.005,-0.000]$} & {$[-0.005,-0.002]$} & {$[0.002,0.006]$} & {$[0.000,0.002]$} \\
E-cigarette tax (any) & 0.000 & -0.001 & $-0.003^{* *}$ & -0.000 \\
& {$[-0.003,0.004]$} & {$[-0.004,0.002]$} & {$[-0.005,-0.001]$} & {$[-0.001,0.000]$} \\
\hline Observations & $3,043,140$ & $3,040,492$ & 847,858 & 847,553 \\
Proportion of outcome variable & 0.157 & 0.112 & 0.031 & 0.011 \\
Number of clusters & 50 & 50 & 50 & 50 \\
\hline Notes: The unit of observation is an individual in a county in a year. Data are unweighted. Models estimated with a \\
linear probability model and control for area-level and individual-level variables reported in Table 1, county fixed- \\
effects, and quarter-by-year fixed effects. 95\% confidence intervals account for within state correlations and are \\
reported in square brackets. \\
***; **; and * = statistically different from zero at the 1\%; 5\%; and 10\% level.
\end{tabular}


Table 4: Effects of traditional cigarette and e-cigarette taxes on smoking and vaping outcomes among adults using a differences-in-differences-style model: NHIS data 2011-2017

\begin{tabular}{lcccc}
\hline \hline Outcome: & Smoking & Daily smoking & Vaping & Daily vaping \\
\hline Traditional cigarette rate (\$ per 20 & $-0.008^{* *}$ & $-0.007^{* *}$ & 0.001 & 0.001 \\
unit pack) & {$[-0.015,-0.000]$} & {$[-0.013,-0.001]$} & {$[-0.004,0.006]$} & {$[-0.002,0.005]$} \\
E-cigarette tax (any) & 0.004 & 0.005 & -0.002 & 0.001 \\
& {$[-0.008,0.016]$} & {$[-0.007,0.016]$} & {$[-0.010,0.006]$} & {$[-0.005,0.007]$} \\
\hline Observations & 220,613 & 220,545 & 121,801 & 121,797 \\
Proportion of outcome variable & 0.176 & 0.135 & 0.031 & 0.011 \\
Number of clusters & 50 & 50 & 50 & 50 \\
\hline Notes: The unit of observation is an individual in a county in a year. Data are unweighted. Models estimated with a \\
linear probability model and control for area-level and individual-level variables reported in Table 1, county fixed- \\
effects, and quarter-by-year fixed effects. 95\% confidence intervals account for within state correlations and are \\
reported in square brackets. \\
***; **; and * = statistically different from zero at the 1\%; 5\%; and 10\% level.
\end{tabular}


Table 5: Effects of traditional cigarette and e-cigarette taxes on smoking and vaping outcomes among adults using an event-study style model: Combined BRFSS and NHIS data 2011-2017

\begin{tabular}{|c|c|c|c|c|}
\hline Outcome: & Smoking & Daily smoking & Vaping & Daily vaping \\
\hline \multicolumn{5}{|l|}{ Large traditional cigarette tax indicators } \\
\hline \multirow{2}{*}{$2+$ years in advance of large tax increase } & 0.003 & 0.003 & 0.004 & -0.003 \\
\hline & {$[-0.004,0.010]$} & {$[-0.002,0.008]$} & {$[-0.003,0.011]$} & {$[-0.007,0.002]$} \\
\hline \multirow[t]{2}{*}{2,1} years in advance of large tax increase & 0.003 & 0.003 & 0.003 & -0.002 \\
\hline & {$[-0.001,0.008]$} & {$[-0.004,0.009]$} & {$[-0.004,0.011]$} & {$[-0.007,0.004]$} \\
\hline \multirow{2}{*}{$\begin{array}{l}{[1,0) \text { years in advance of large tax increase }} \\
\text { (reference) }\end{array}$} & -- & -- & -- & -- \\
\hline & -- & -- & -- & -- \\
\hline \multirow{2}{*}{ Tax increase } & -0.000 & $-0.003 * *$ & $0.004^{* *}$ & 0.001 \\
\hline & {$[-0.004,0.004]$} & {$[-0.006,-0.000]$} & {$[0.000,0.008]$} & {$[-0.002,0.004]$} \\
\hline \multicolumn{5}{|l|}{ E-cigarette tax indicators } \\
\hline \multirow[t]{2}{*}{$2+$ years in advance of tax adoption } & -0.001 & 0.001 & -0.004 & -0.001 \\
\hline & {$[-0.007,0.004]$} & {$[-0.004,0.005]$} & {$[-0.010,0.002]$} & {$[-0.004,0.003]$} \\
\hline \multirow{2}{*}{2,1} years in advance of tax adoption & -0.001 & -0.000 & -0.004 & -0.002 \\
\hline & {$[-0.006,0.004]$} & {$[-0.005,0.005]$} & {$[-0.010,0.002]$} & {$[-0.006,0.002]$} \\
\hline \multirow{2}{*}{$\begin{array}{l}{[1,0) \text { years in advance of tax adoption }} \\
\text { (reference) }\end{array}$} & -- & -- & -- & -- \\
\hline & -- & -- & -- & -- \\
\hline \multirow[t]{2}{*}{ Tax adoption } & -0.002 & -0.000 & -0.003 & -0.000 \\
\hline & {$[-0.006,0.002]$} & {$[-0.005,0.004]$} & {$[-0.006,0.001]$} & {$[-0.003,0.002]$} \\
\hline Observations & $3,016,967$ & $3,014,425$ & 906,116 & 905,826 \\
\hline Proportion of outcome variable & 0.159 & 0.115 & 0.031 & 0.011 \\
\hline Number of clusters & 47 & 47 & 47 & 47 \\
\hline
\end{tabular}

Notes: The unit of observation is an individual in a county in a year. Data are unweighted. Models estimated with a linear probability model and control for area-level and individual-level variables reported in Table 1, county fixedeffects, and quarter-by-year fixed effects. 95\% confidence intervals account for within state correlations and are reported in square brackets. The omitted category is the year prior to the policy adoption. A large traditional cigarette tax hike is defined as an increase of $\geq \$ 0.50$. All non-adopting localities are coded as zero for all eventtime indicators. Illinois, Massachusetts, and Minnesota are excluded; see text for details. $* * * ; * *$; and $*=$ statistically different from zero at the $1 \%$; $5 \%$; and $10 \%$ level. 
Table 6: Effects of traditional cigarette and e-cigarette taxes on smoking and vaping outcomes among adults using a differences-in-differences-style model among males: Combined BRFSS and NHIS data 2011-2017

\begin{tabular}{lcccc}
\hline \hline Outcome: & Smoking & Daily smoking & Vaping & Daily vaping \\
\hline Traditional cigarette rate (\$ per 20 & $-0.006^{* * *}$ & $-0.006^{* * *}$ & $0.005^{* * *}$ & $0.002^{* *}$ \\
unit pack) & {$[-0.010,-0.002]$} & {$[-0.008,-0.003]$} & {$[0.002,0.008]$} & {$[0.000,0.004]$} \\
E-cigarette tax (any) & 0.000 & -0.000 & $-0.005^{* *}$ & 0.000 \\
& {$[-0.005,0.006]$} & {$[-0.005,0.005]$} & {$[-0.009,-0.001]$} & {$[-0.002,0.002]$} \\
\hline Observations & $1,356,202$ & $1,354,866$ & 422,839 & 422,657 \\
Proportion of outcome variable & 0.175 & 0.126 & 0.036 & 0.013 \\
Number of clusters & 50 & 50 & 50 & 50 \\
\hline Notes: The unit of observation is an individual in a county in a year. Data are unweighted. Models estimated with a \\
linear probability model and control for area-level and individual-level variables reported in Table 1, county fixed- \\
effects, and quarter-by-year fixed effects. 95\% confidence intervals account for within state correlations and are \\
reported in square brackets. \\
***; **; and * = statistically different from zero at the 1\%; 5\%; and 10\% level.
\end{tabular}


Table 7: Effects of traditional cigarette and e-cigarette taxes on smoking and vaping outcomes among adults using a differences-in-differences-style model among females: Combined BRFSS and NHIS data 2011-2017

\begin{tabular}{lcccc}
\hline Outcome: & Smoking & Daily smoking & Vaping & Daily vaping \\
\hline Traditional cigarette rate (\$ per 20 & -0.001 & -0.002 & 0.001 & 0.001 \\
unit pack) & {$[-0.005,0.002]$} & {$[-0.005,0.001]$} & {$[-0.002,0.005]$} & {$[-0.001,0.002]$} \\
E-cigarette tax (any) & 0.000 & -0.001 & -0.000 & -0.001 \\
& {$[-0.005,0.005]$} & {$[-0.004,0.002]$} & {$[-0.004,0.004]$} & {$[-0.002,0.000]$} \\
\hline Observations & $1,907,267$ & $1,905,887$ & 546,537 & 546,410 \\
Proportion of outcome variable & 0.147 & 0.105 & 0.027 & 0.009 \\
Number of clusters & 50 & 50 & 50 & 50 \\
\hline
\end{tabular}

Notes: The unit of observation is an individual in a county in a year. Data are unweighted. Models estimated with a linear probability model and control for area-level and individual-level variables reported in Table 1, county fixedeffects, and quarter-by-year fixed effects. 95\% confidence intervals account for within state correlations and are reported in square brackets.

***; **; and * = statistically different from zero at the $1 \%$; $5 \%$; and $10 \%$ level. 
Table 8: Effects of traditional cigarette and e-cigarette taxes on smoking and vaping outcomes among adults using a differences-in-differences-style model among adults less than 35 years: Combined BRFSS and NHIS data 2011-2017

\begin{tabular}{lcccc}
\hline \hline Outcome: & Smoking & Daily smoking & Vaping & Daily vaping \\
\hline Traditional cigarette rate (\$ per 20 & $-0.005^{*}$ & $-0.006^{* *}$ & $0.006^{* *}$ & 0.002 \\
unit pack) & {$[-0.010,0.000]$} & {$[-0.011,-0.001]$} & {$[0.000,0.011]$} & {$[-0.002,0.006]$} \\
E-cigarette tax (any) & -0.003 & -0.003 & -0.006 & 0.000 \\
& {$[-0.012,0.006]$} & {$[-0.009,0.004]$} & {$[-0.013,0.002]$} & {$[-0.005,0.006]$} \\
\hline Observations & 495,401 & 495,147 & 156,489 & 156,395 \\
Proportion of outcome variable & 0.217 & 0.145 & 0.064 & 0.022 \\
Number of clusters & 50 & 50 & 50 & 50 \\
\hline
\end{tabular}

Notes: The unit of observation is an individual in a county in a year. Data are unweighted. Models estimated with a linear probability model and control for area-level and individual-level variables reported in Table 1, county fixedeffects, and quarter-by-year fixed effects. 95\% confidence intervals account for within state correlations and are reported in square brackets.

$* * * ; * *$; and $*=$ statistically different from zero at the $1 \%$; $5 \%$; and $10 \%$ level. 
Table 9: Effects of traditional cigarette and e-cigarette taxes on any smoking among adults using a differences-in-differences-style model including an interaction between the traditional cigarette tax rate and the indicator for an e-cigarette tax: Combined BRFSS and NHIS data 2011-2017

\begin{tabular}{lcccc}
\hline \hline Sample: & Full sample & Males & Females & $<$ 35 years \\
\hline Traditional cigarette rate (\$ per 20 & $-0.004^{* * *}$ & $-0.008^{* * *}$ & -0.002 & $-0.007^{*}$ \\
unit pack) & {$[-0.007,-0.001]$} & {$[-0.013,-0.003]$} & {$[-0.006,0.003]$} & {$[-0.013,0.000]$} \\
E-cigarette tax (any) & -0.002 & -0.006 & -0.000 & -0.007 \\
& {$[-0.007,0.004]$} & {$[-0.014,0.002]$} & {$[-0.009,0.009]$} & {$[-0.020,0.007]$} \\
Traditional cigarette tax rate $(\$)^{*}$ & 0.002 & $0.005^{*}$ & 0.000 & 0.003 \\
e-cigarette tax (any) & {$[-0.001,0.005]$} & {$[-0.000,0.010]$} & {$[-0.005,0.005]$} & {$[-0.005,0.010]$} \\
\hline Observations & $3,263,753$ & $1,356,202$ & $1,907,267$ & 495,401 \\
Proportion of outcome variable & 0.158 & 0.175 & 0.147 & 0.217 \\
Number of clusters & 50 & 50 & 50 & 50 \\
\hline Notes: The unit of observation is an individual in a county in a year. Data are unweighted. Models estimated with a \\
linear probability model and control for area-level and individual-level variables reported in Table 1, county fixed- \\
effects, and quarter-by-year fixed effects. 95\% confidence intervals account for within state correlations and are \\
reported in square brackets. \\
***; **; and * = statistically different from zero at the 1\%; 5\%; and 10\% level.
\end{tabular}


Table 10: Effects of traditional cigarette and e-cigarette taxes on daily smoking among adults using a differences-in-differences-style model including an interaction between the traditional cigarette tax rate and the indicator for an e-cigarette tax: Combined BRFSS and NHIS data 2011-2017

\begin{tabular}{lcccc}
\hline \hline Sample: & Full sample & Males & Females & $<$ 35 years \\
\hline Traditional cigarette rate (\$ per 20 & $-0.006^{* * *}$ & $-0.009^{* * *}$ & $-0.004^{*}$ & $-0.009^{* * *}$ \\
unit pack) & {$[-0.008,-0.003]$} & {$[-0.013,-0.004]$} & {$[-0.008,0.000]$} & {$[-0.015,-0.003]$} \\
E-cigarette tax (any) & $-0.005^{* * *}$ & $-0.006^{*}$ & $-0.005^{* * *}$ & $-0.010^{*}$ \\
& {$[-0.008,-0.002]$} & {$[-0.014,0.001]$} & {$[-0.008,-0.002]$} & {$[-0.020,0.000]$} \\
Traditional cigarette tax rate (\$ per 20 & $0.004^{* * *}$ & $0.005^{* *}$ & $0.003^{*}$ & $0.006^{*}$ \\
unit pack)*e-cigarette tax (any) & {$[0.001,0.006]$} & {$[0.001,0.009]$} & {$[-0.000,0.006]$} & {$[-0.001,0.012]$} \\
\hline Observations & $3,261,037$ & $1,354,866$ & $1,905,887$ & 495,147 \\
Proportion of outcome variable & 0.114 & 0.126 & 0.105 & 0.145 \\
Number of clusters & 50 & 50 & 50 & 50 \\
\hline Notes: The unit of observation is an individual in a county in a year. Data are unweighted. Models estimated with a \\
linear probability model and control for area-level and individual-level variables reported in Table 1, county fixed- \\
effects, and quarter-by-year fixed effects. 95\% confidence intervals account for within state correlations and are \\
reported in square brackets. \\
***; **; and * = statistically different from zero at the 1\%; 5\%; and 10\% level.
\end{tabular}


Figure 1. Geographic variation in locality traditional cigarette taxes 2017

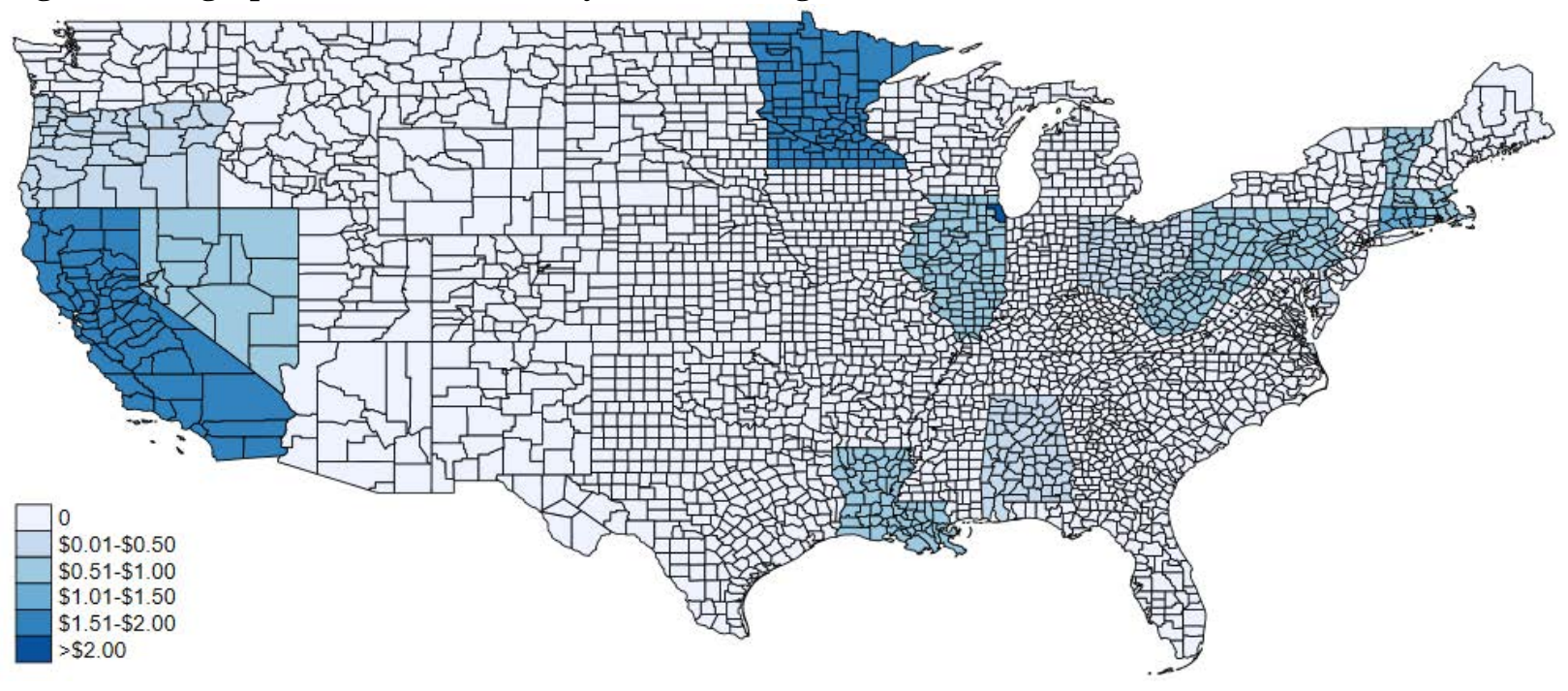

Notes: See text for details. 
Figure 2. Geographic variation in localities that adopted an e-cigarette tax by 2017

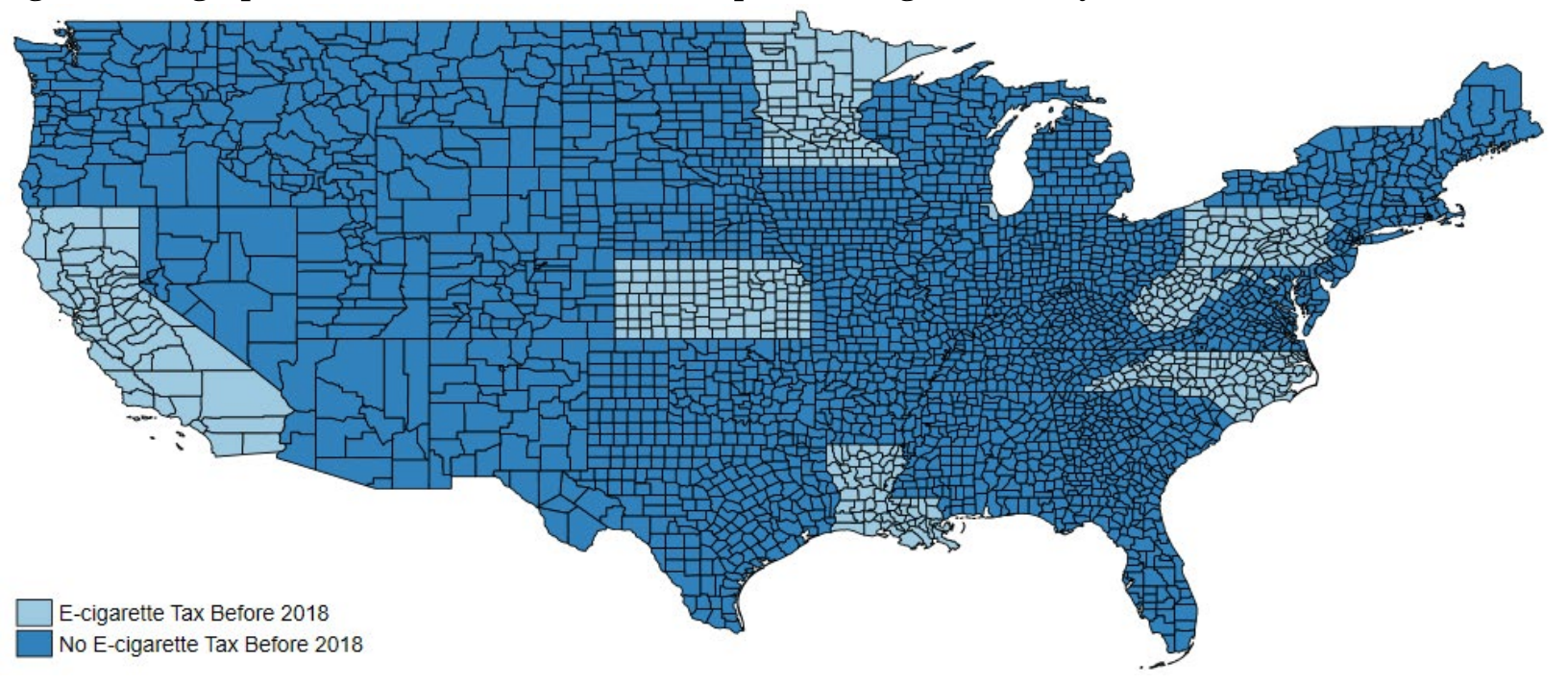

Notes: See text for details. 
Figure 3. Traditional cigarette tax changes in each year 2011 to 2017

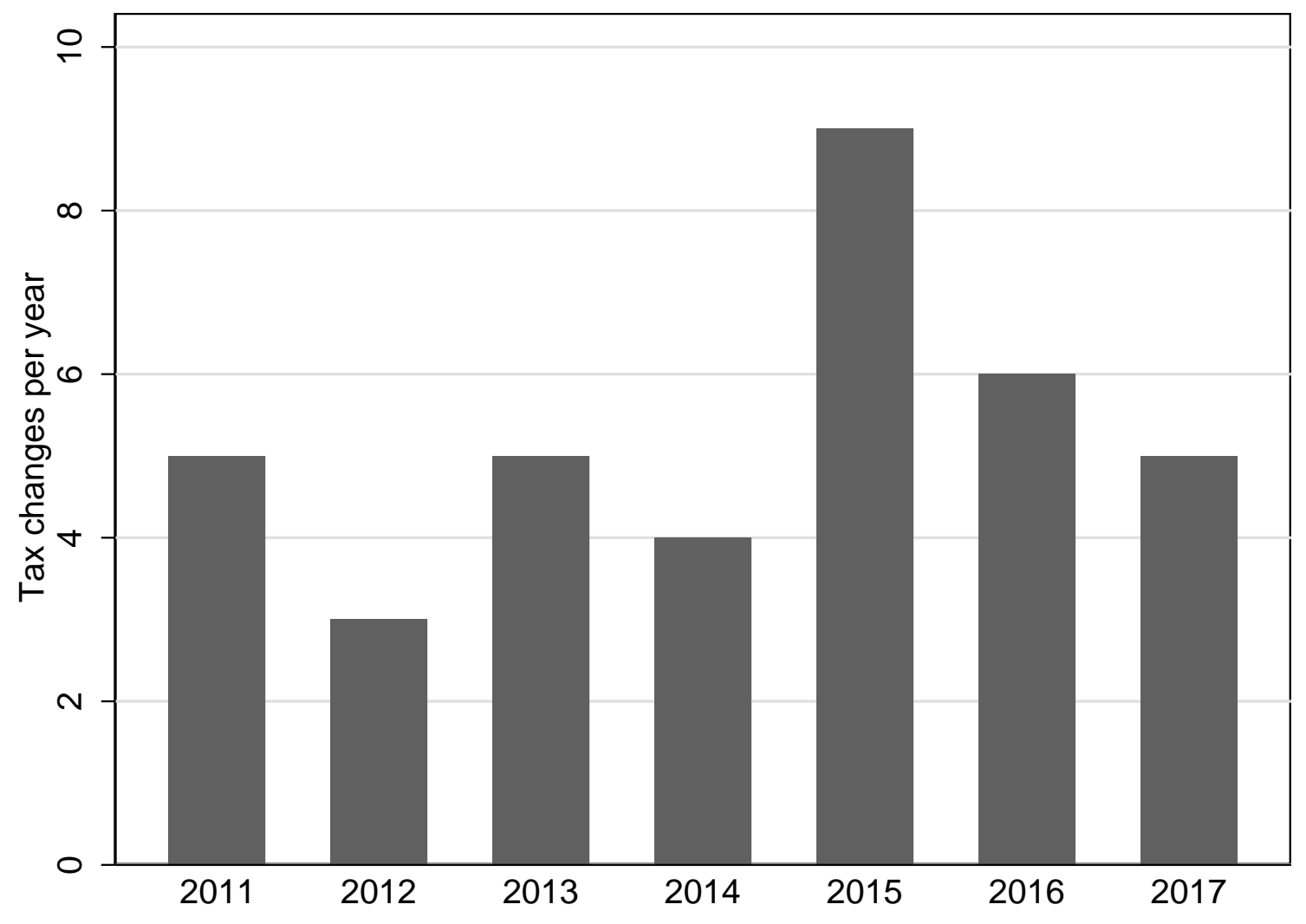

Notes: See text for details. 
Figure 4. E-cigarette tax adoptions in each year 2011 to 2017

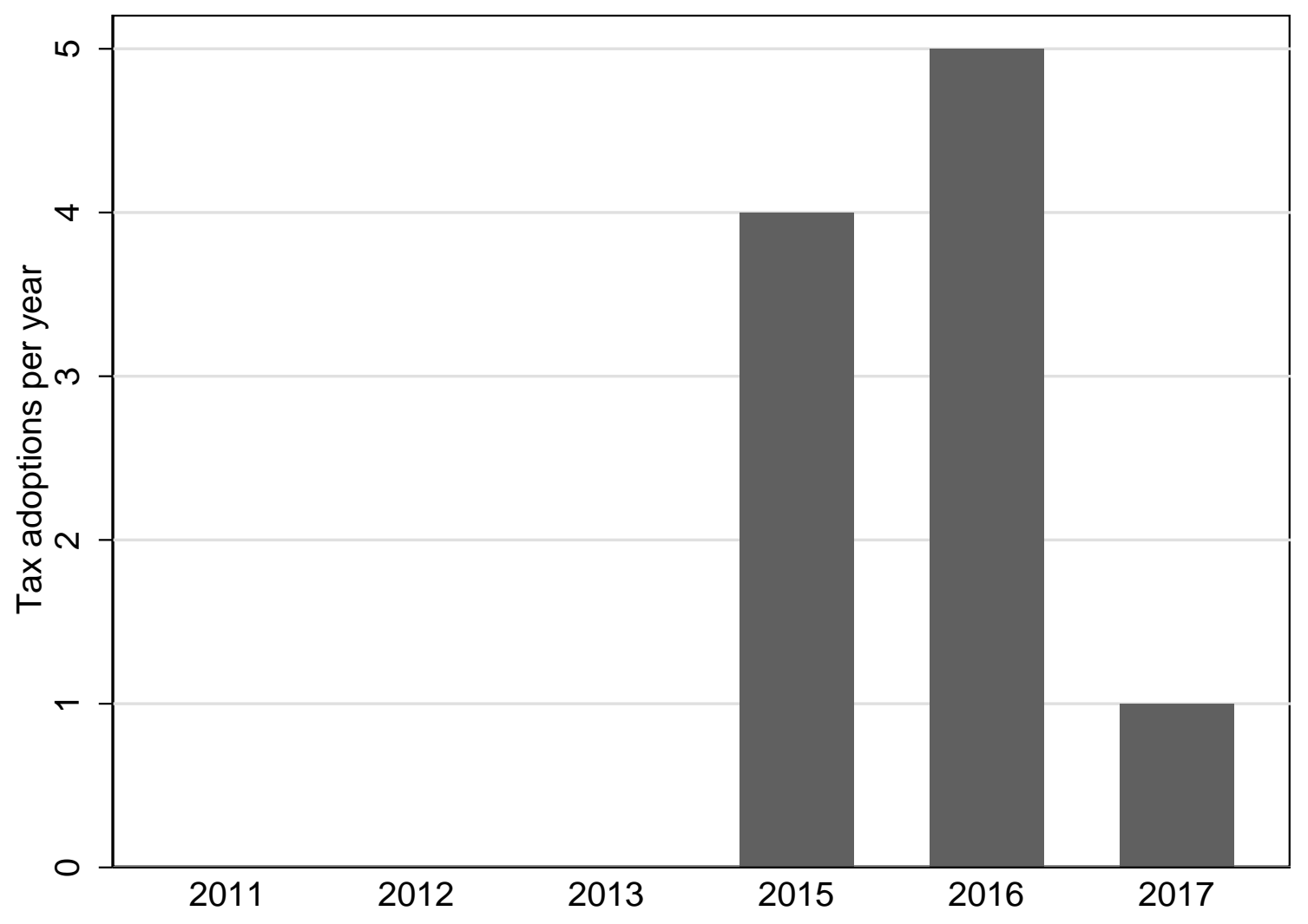

Notes: See text for details. 
Appendix Table 1. Traditional cigarette tax changes 2011-2017

\begin{tabular}{l|c|c}
\hline \hline Locality & Effective date & Tax change amount* \\
\hline State & & \\
\hline Alabama & $10 / 2015$ & $\$ 0.25$ \\
California & $4 / 2017$ & $\$ 2.00$ \\
Connecticut & $7 / 2011,10 / 2015,7 / 2016,12 / 2017$ & $\$ 0.40, \$ \$ 0.25, \$ 0.25, \$ 0.45$ \\
Delaware & $9 / 2017$ & $\$ 0.50$ \\
Hawaii & $7 / 2011$ & $\$ 0.20$ \\
Illinois & $6 / 2012$ & $\$ 1.00$ \\
Kansas & $7 / 2015$ & $\$ 0.50$ \\
Louisiana & $7 / 2015,4 / 2016$ & $\$ 0.50, \$ 0.22$ \\
Massachusetts & $7 / 2013$ & $\$ 1.00$ \\
Minnesota & $7 / 2015,1 / 2016,1 / 2017$ & $\$ 1.60, \$ 0.07, \$ 0.10, \$ 0.04$ \\
New Hampshire & $7 / 2015$ & $-\$ 0.10, \$ 0.10$, \\
Ohio & $1 / 2014,1 / 2016$ & $\$ 0.35$ \\
Oregon & $7 / 2015$ & $\$ 0.13, \$ 0.01$ \\
Nevada & $8 / 2016$ & $\$ 1.00$ \\
Pennsylvania & $7 / 2016$ & $\$ 1.00$ \\
Rhode Island & $7 / 2012,8 / 2015,8017$ & $\$ 0.04, \$ 0.25, \$ 0.50$ \\
West Virginia & & $\$ 0.65$ \\
Vermont & $1 / 2014$ & \\
\hline County/City** & $3 / 2013$ & $\$ 0.50 .30$ \\
\hline Chicago, Illinois & $7 / 2011,7 / 2012$ & $\$ 1.00$ \\
Cook County, Illinois & $1 / 2014$ & $\$ 0.10, \$ 0.10$ \\
Newport News, Virginia & $7 / 2013$ & $\$ 2.00$ \\
Philadelphia County, Pennsylvania & & $\$ 0.05$ \\
Virginia Beach, Virginia & $7 / 2014,7 / 2015$ & \\
\hline
\end{tabular}

Notes: See text for full details.

*This number indicates the size of the change in the tax, not the level of the tax after accounting for the change.

**For locations with 100,000 people or more. 
Appendix Table 2. E-cigarette tax adoption through end of 2017

\begin{tabular}{l|c|c|c}
\hline Locality & Effective date & Unit taxed & Tax amount \\
\hline State & & & \\
\hline District of Columbia & $10 / 2015,10 / 2016$ & Wholesale price & $67 \%, 65 \%$ \\
California & $4 / 2017,7 / 2017$ & Wholesale price & $27.3 \%, 65.1 \%$ \\
Kansas & $7 / 2016,7 / 2017$ & Per fluid milliliter & $\$ 0.20, \$ 0.05$ \\
Louisiana & $7 / 2015$ & Per fluid milliliter & $\$ 0.05$ \\
Minnesota & $8 / 2010,7 / 2013$ & Wholesale price & $35 \%, 95 \%$ \\
North Carolina & $6 / 2015$ & Per fluid milliliter & $\$ 0.05$ \\
Pennsylvania & $7 / 2016$ & Purchase price & $40 \%$ \\
West Virginia & $7 / 2016$ & Per fluid milliliter & $\$ 0.075$ \\
\hline County/City & & & \\
Chicago, Illinois & $1 / 2016$ & Per unit / per fluid milliliter & $\$ 0.80 / \$ 0.55$ \\
Cook County, Illinois & $5 / 2016$ & Per fluid milliliter & $\$ 0.20$ \\
Montgomery County, Maryland & $8 / 2015$ & Wholesale price & $30 \%$ \\
\hline
\end{tabular}

Notes: See text for full details. Minnesota is a treated control for our study period. Delaware and New Jersey levied e-cigarette taxes after 2017 (details available on request). We do not incorporate these changes into our analysis. 
Appendix Table 3: Summary statistics among respondents in all localities, and localities that did and did not adopt an e-cigarette tax by 2017: BRFSS data 2011-2017

\begin{tabular}{|c|c|c|c|}
\hline Sample: & $\begin{array}{c}\text { All } \\
\text { localities }\end{array}$ & $\begin{array}{l}\text { Adopting } \\
\text { localities }\end{array}$ & $\begin{array}{c}\text { Non-adopting } \\
\text { localities }\end{array}$ \\
\hline \multicolumn{4}{|l|}{ Outcomes: } \\
\hline Smoking & 0.157 & 0.160 & 0.157 \\
\hline Daily smoking & 0.112 & 0.114 & 0.112 \\
\hline Vaping & 0.031 & 0.030 & 0.031 \\
\hline Daily vaping & 0.011 & 0.011 & 0.011 \\
\hline \multicolumn{4}{|l|}{ Traditional cigarette and e-cigarette taxes } \\
\hline Traditional cigarette tax rate (\$ per pack) & $1.449(0.922)$ & $1.273(0.802)$ & $1.490(0.943)$ \\
\hline E-cigarette tax (any) & 0.064 & 0.344 & 0.000 \\
\hline \multicolumn{4}{|l|}{ Area-level controls } \\
\hline Restaurant smoking ban & 0.700 & 0.688 & 0.702 \\
\hline Private workplace smoking ban & 0.705 & 0.713 & 0.703 \\
\hline Bar smoking ban & 0.590 & 0.609 & 0.585 \\
\hline Indoor vaping restrictions (\% population) & $0.139(0.320)$ & $0.134(0.305)$ & $0.140(0.323)$ \\
\hline Beer tax (\$ per gallon) & $0.237(0.201)$ & $0.169(0.102)$ & $0.252(0.214)$ \\
\hline Medical marijuana law & 0.408 & 0.333 & 0.425 \\
\hline Marijuana decriminalized & 0.328 & 0.185 & 0.361 \\
\hline Prescription drug monitoring program & 0.948 & 0.959 & 0.946 \\
\hline ACA-Medicaid expansion & 0.312 & 0.315 & 0.311 \\
\hline Unemployment rate (\%) & $5.961(2.013)$ & $6.273(2.075)$ & $5.890(1.992)$ \\
\hline \multicolumn{4}{|l|}{ Individual-level controls } \\
\hline Female & 0.597 & 0.584 & 0.599 \\
\hline Male & 0.403 & 0.416 & 0.401 \\
\hline Less than high school & 0.080 & 0.081 & 0.079 \\
\hline High school or GED & 0.281 & 0.266 & 0.285 \\
\hline Some college & 0.271 & 0.264 & 0.272 \\
\hline College degree or more & 0.363 & 0.384 & 0.359 \\
\hline Education missing & 0.005 & 0.005 & 0.005 \\
\hline White & 0.836 & 0.819 & 0.840 \\
\hline African American & 0.087 & 0.106 & 0.082 \\
\hline Asian & 0.015 & 0.022 & 0.014 \\
\hline Native American or Alaskan & 0.020 & 0.016 & 0.021 \\
\hline Other race & 0.023 & 0.023 & 0.023 \\
\hline Race missing & 0.019 & 0.014 & 0.020 \\
\hline Married & 0.536 & 0.527 & 0.538 \\
\hline Divorced & 0.142 & 0.138 & 0.142 \\
\hline Widowed & 0.134 & 0.123 & 0.137 \\
\hline Separated & 0.021 & 0.022 & 0.021 \\
\hline Never married & 0.160 & 0.184 & 0.155 \\
\hline Marital status missing & 0.007 & 0.006 & 0.007 \\
\hline Age (years) & $56.12(16.42)$ & $54.83(16.63)$ & $56.42(16.38)$ \\
\hline Uninsured & 0.092 & 0.094 & 0.091 \\
\hline Insured & 0.905 & 0.903 & 0.906 \\
\hline Insurance missing & 0.003 & 0.003 & 0.003 \\
\hline Income (\$; missing values imputed) & $46,334(24,636)$ & $47,151(25,031)$ & $46,147(24,540)$ \\
\hline Unemployed or not in labor force & 0.499 & 0.475 & 0.504 \\
\hline Employed & 0.494 & 0.517 & 0.488 \\
\hline Employment missing & 0.008 & 0.008 & 0.008 \\
\hline Observations & $3,140,962$ & 585,620 & $2,555,342$ \\
\hline
\end{tabular}

Notes: Data are unweighted. The unit of observation is an individual in a county in a year. Standard deviations for continuous variables are reported in parentheses. 
Appendix table 4: Summary statistics among respondents in all localities, and localities that did and did not adopt an e-cigarette tax by 2017: NHIS data 2011-2017

\begin{tabular}{|c|c|c|c|}
\hline Sample: & $\begin{array}{c}\text { All } \\
\text { localities }\end{array}$ & $\begin{array}{l}\text { Adopting } \\
\text { localities }\end{array}$ & $\begin{array}{c}\text { Non-adopting } \\
\text { localities }\end{array}$ \\
\hline \multicolumn{4}{|l|}{ Outcomes: } \\
\hline Smoking & 0.176 & 0.158 & 0.182 \\
\hline Daily smoking & 0.135 & 0.116 & 0.141 \\
\hline Vaping & 0.031 & 0.026 & 0.032 \\
\hline Daily vaping & 0.011 & 0.009 & 0.012 \\
\hline \multicolumn{4}{|l|}{ Traditional cigarette and e-cigarette taxes } \\
\hline Traditional cigarette tax rate (\$ per pack) & $1.420(0.946)$ & $1.143(0.734)$ & $1.519(0.993)$ \\
\hline E-cigarette tax (any) & 0.055 & 0.210 & 0.000 \\
\hline \multicolumn{4}{|l|}{ Area-level controls } \\
\hline Restaurant smoking ban & 0.586 & 0.444 & 0.637 \\
\hline Private workplace smoking ban & 0.598 & 0.464 & 0.646 \\
\hline Bar smoking ban & 0.468 & 0.390 & 0.496 \\
\hline Indoor vaping restrictions (\% population) & $0.128(0.304)$ & $0.157(0.316)$ & $0.118(0.299)$ \\
\hline Beer tax (\$ per gallon) & $0.233(0.194)$ & $0.175(0.076)$ & $0.253(0.217)$ \\
\hline Medical marijuana law & 0.429 & 0.593 & 0.370 \\
\hline Marijuana decriminalized & 0.363 & 0.494 & 0.317 \\
\hline Prescription drug monitoring program & 0.952 & 0.969 & 0.946 \\
\hline ACA-Medicaid expansion & 0.322 & 0.412 & 0.290 \\
\hline Unemployment rate (\%) & $6.445(2.098)$ & $7.269(2.254)$ & $6.152(1.958)$ \\
\hline \multicolumn{4}{|l|}{ Individual-level controls } \\
\hline Female & 0.528 & 0.528 & 0.528 \\
\hline Male & 0.472 & 0.472 & 0.472 \\
\hline Less than high school & 0.144 & 0.169 & 0.135 \\
\hline High school or GED & 0.263 & 0.242 & 0.270 \\
\hline Some college & 0.290 & 0.273 & 0.296 \\
\hline College degree or more & 0.289 & 0.299 & 0.285 \\
\hline Education missing & 0.015 & 0.018 & 0.014 \\
\hline White & 0.775 & 0.721 & 0.795 \\
\hline African American & 0.132 & 0.133 & 0.131 \\
\hline Asian & 0.064 & 0.114 & 0.046 \\
\hline Native American or Alaskan & 0.012 & 0.012 & 0.011 \\
\hline Other race & 0.018 & 0.020 & 0.017 \\
\hline Race missing & 0.000 & 0.000 & 0.000 \\
\hline Married & 0.569 & 0.559 & 0.573 \\
\hline Divorced & 0.115 & 0.101 & 0.120 \\
\hline Widowed & 0.064 & 0.060 & 0.065 \\
\hline Separated & 0.025 & 0.027 & 0.024 \\
\hline Never married & 0.223 & 0.248 & 0.214 \\
\hline Marital status missing & 0.004 & 0.004 & 0.003 \\
\hline Age (years) & $48.50(16.75)$ & 47.65 (16.59) & $48.81(16.79)$ \\
\hline Uninsured & 0.145 & 0.153 & 0.142 \\
\hline Insured & 0.845 & 0.835 & 0.848 \\
\hline Insurance missing & 0.010 & 0.013 & 0.010 \\
\hline Income (\$;missing values imputed) & $21,736(23,331)$ & $21,971(23,730)$ & $21,652(23,186)$ \\
\hline Unemployed or not in labor force & 0.375 & 0.373 & 0.376 \\
\hline Employed & 0.618 & 0.618 & 0.618 \\
\hline Employment missing & 0.007 & 0.009 & 0.006 \\
\hline Observations & 496,859 & 130,439 & 366,420 \\
\hline
\end{tabular}

Notes: Data are unweighted. The unit of observation is an individual in a county in a year. Standard deviations for continuous variables are reported in parentheses 


\section{References:}

Abouk, R., and S. Adams. 2017. "Bans on Electronic Cigarette Sales to Minors and Smoking among High School Students." Journal of Health Economics 54:17-24.

Ali, M. M., W. N. Dowd, T. Classen, R. Mutter, and S. P. Novak. 2017. "Prescription Drug Monitoring Programs, Nonmedical Use of Prescription Drugs, and Heroin Use: Evidence from the National Survey of Drug Use and Health." Addictive Behaviors 69:65-77.

Altonji, J. G., L. B. Kahn, and J. D. Speer. 2016. "Cashier or Consultant? Entry Labor Market Conditions, Field of Study, and Career Success." Journal of Labor Economics 34 (S1):S361-S401.

Autor, D. H. 2003. "Outsourcing at Will: The Contribution of Unjust Dismissal Doctrine to the Growth of Employment Outsourcing." Journal of Labor Economics 21 (1):1-42.

Barbaresco, S., C. J. Courtemanche, and Y. Qi. 2015. "Impacts of the Affordable Care Act Dependent Coverage Provision on Health-Related Outcomes of Young Adults." Journal of Health Economics 40:54-68.

Bertrand, M., E. Duflo, and S. Mullainathan. 2004. "How Much Should We Trust Differencesin-Differences Estimates?" Quarterly Journal of Economics 119 (1):249-275.

Besley, T., and A. Case. 2000. "Unnatural Experiments? Estimating the Incidence of Endogenous Policies." The Economic Journal 110 (467):672-694.

Bishop, J. M. 2018. "Does Cigarette Smuggling Prop up Smoking Rates?" American Journal of Health Economics 4 (1):80-104.

Bradford, A. C., and W. D. Bradford. 2018. "The Impact of Medical Cannabis Legalization on Prescription Medication Use and Costs under Medicare Part D." The Journal of Law and Economics 61 (3):461-487.

Burns, M., and L. Dague. 2017. "The Effect of Expanding Medicaid Eligibility on Supplemental Security Income Program Participation." Journal of Public Economics 149:20-34.

Callison, K., and R. Kaestner. 2014. "Do Higher Tobacco Taxes Reduce Adult Smoking? New Evidence of the Effect of Recent Cigarette Tax Increases on Adult Smoking " Economic Inquiry 52 (1):155-172.

Cantrell, J., J. Huang, M. S. Greenberg, H. Xiao, E. C. Hair, and D. Vallone. 2019. "Impact of ECigarette and Cigarette Prices on Youth and Young Adult E-Cigarette and Cigarette Behaviour: Evidence from a National Longitudinal Cohort." Tobacco Control:tobaccocontrol-2018-054764.

Carpenter, C., and P. J. Cook. 2008. "Cigarette Taxes and Youth Smoking: New Evidence from National, State, and Local Youth Risk Behavior Surveys." Journal of Health Economics 27 (2):287-299.

Centers for Disease Control and Prevention. 2019. Cdc State System.

Chaloupka, F. J., and K. E. Warner. 2000. "The Economics of Smoking." In Handbook of Health Economics, edited by A. J. Culyer and J. P. Newhouse 1539-1627.

Community Preventive Services Task Force. 2014. Reducing Tobacco Use and Secondhand Smoke Exposure: Interventions to Increase the Unit Price for Tobacco Products.

Cooper, M. T., and M. F. Pesko. 2017. "The Effect of E-Cigarette Indoor Vaping Restrictions on Adult Prenatal Smoking and Birth Outcomes." Journal of Health Economics 56:178-190.

Cotti, C., E. Nesson, and N. Tefft. 2016. "The Effects of Tobacco Control Policies on Tobacco Products, Tar, and Nicotine Purchases among Adults: Evidence from Household Panel Data." American Economic Journal: Economic Policy 8 (4):103-23. 
Cotti, C., E. Nesson, and N. Tefft. 2018. "The Relationship between Cigarettes and Electronic Cigarettes: Evidence from Household Panel Data." Journal of Health Economics 61:205219.

Courtemanche, C., and B. Feng. 2018. Can Cigarette Taxes Still Reduce Youth Smoking?

Dave, D., B. Feng, and M. F. Pesko. 2019. "The Effects of E-Cigarette Minimum Legal Sale Age Laws on Youth Substance Use." Health Economics 28 (3):419-436.

DeCicca, P., D. Kenkel, and A. Mathios. 2002. "Putting out the Fires: Will Higher Taxes Reduce the Onset of Youth Smoking?" Journal of Political Economy 110 (1):144-169.

DeCicca, P., and L. McLeod. 2008. "Cigarette Taxes and Older Adult Smoking: Evidence from Recent Large Tax Increases." Journal of Health Economics 27 (4):918-929.

Farber, H. S., D. Herbst, I. Kuziemko, and S. Naidu. 2018. Unions and Inequality over the Twentieth Century: New Evidence from Survey Data. National Bureau of Economic Research.

Friedman, A. S. 2015. "How Does Electronic Cigarette Access Affect Adolescent Smoking?" Journal of Health Economics.

Glasser, A. M., L. Collins, J. L. Pearson, H. Abudayyeh, R. S. Niaura, D. B. Abrams, and A. C. Villanti. 2017. "Overview of Electronic Nicotine Delivery Systems: A Systematic Review." American Journal of Preventive Medicine 52 (2):e33-e66.

Gostin, L. O. 2017. "2016: The Year of the Soda Tax." The Milbank Quarterly 95 (1):19.

Gruber, J., and M. Frakes. 2006. "Does Falling Smoking Lead to Rising Obesity?" Journal of Health Economics 25 (2):183-197.

Gruber, J., and B. Köszegi. 2001. "Is Addiction "Rational”? Theory and Evidence." The Quarterly Journal of Economics 116 (4):1261-1303.

Hajek, P., A. Phillips-Waller, D. Przulj, F. Pesola, K. Myers Smith, N. Bisal, J. Li, S. Parrott, P. Sasieni, and L. Dawkins. 2019. "A Randomized Trial of E-Cigarettes Versus NicotineReplacement Therapy." New England Journal of Medicine 380 (7):629-637.

Hansen, B., J. J. Sabia, and D. I. Rees. 2017. "Have Cigarette Taxes Lost Their Bite? New Estimates of the Relationship between Cigarette Taxes and Youth Smoking." American Journal of Health Economics 3 (1):60-75.

Harrell, P. T., N. S. Marquinez, J. B. Correa, L. R. Meltzer, M. Unrod, S. K. Sutton, V. N. Simmons, and T. H. Brandon. 2014. "Expectancies for Cigarettes, E-Cigarettes, and Nicotine Replacement Therapies among E-Cigarette Users (Aka Vapers)." Nicotine \& Tobacco Research 17 (2):193-200.

Horn, B. P., J. C. Maclean, and M. R. Strain. 2017. "Do Minimum Wage Increases Influence Worker Health?" Economic Inquiry 55 (4):1986-2007.

Huang, J., C. Gwarnicki, X. Xu, R. S. Caraballo, R. Wada, and F. J. Chaloupka. 2018. "A Comprehensive Examination of Own-and Cross-Price Elasticities of Tobacco and Nicotine Replacement Products in the Us." Preventive Medicine 117:107-114.

Lovenheim, M. F. 2009. "The Effect of Teachers' Unions on Education Production: Evidence from Union Election Certifications in Three Midwestern States." Journal of Labor Economics 27 (4):525-587.

Maclean, J. C., A. S. Kessler, and D. S. Kenkel. 2016. "Cigarette Taxes and Older Adult Smoking: Evidence from the Health and Retirement Study." Health Economics 25 (4):424-38.

Maclean, J. C., M. Oney, J. Marti, and J. Sindelar. 2018. "What Factors Predict the Passage of State-Level E-Cigarette Regulations?" Health Economics 27 (5):897-907. 
Maclean, J. C., M. F. Pesko, and S. C. Hill. 2019. "Public Insurance Expansions and Smoking Cessation Medications." Economic Inquiry Accepted.

Maclean, J. C., D. S. Tello-Trillo, and D. Webber. 2019. Losing Insurance and Behavioral Health Inpatient Care: Evidence from a Large-Scale Medicaid Disenrollment. Cambridge, MA: National Bureau of Economic Research.

Marti, J., J. Buckell, J. C. Maclean, and J. Sindelar. 2019. "To "Vape” or Smoke? Experimental Evidence on Adult Smokers." Economic Inquiry 57 (1):705-725.

McInerney, M., and K. Simon. 2012. "The Effect of State Workers' Compensation Program Changes on the Use of Federal Social Security Disability Insurance." Industrial Relations: A Journal of Economy and Society 51 (1):57-88.

Miller, S. 2012. "The Effect of Insurance on Emergency Room Visits: An Analysis of the 2006 Massachusetts Health Reform." Journal of Public Economics 96 (11-12):893-908.

Miller, S., and L. R. Wherry. 2017. "Health and Access to Care During the First 2 Years of the Aca Medicaid Expansions." New England Journal of Medicine 376 (10):947-956.

National Institute on Alcohol Abuse and Alcoholism. 2019. Alcohol Policy Information System (Apis): Beer Taxes.

Nesson, E. 2017. "Heterogeneity in Smokers' Responses to Tobacco Control Policies." Health Economics 26 (2):206-225.

Orzechowski, W., and R. Walker. 2018. The Tax Burden on Tobacco 2017: Historical Compilation. Arlington, VA.

Pacula, R. L., J. F. Chriqui, and J. King. 2003. Marijuana Decriminalization: What Does It Mean in the United States? In National Bureau of Economic Research Working Paper Series. Cambridge, MA: National Bureau of Economic Research.

Page, M. E., J. Spetz, and J. Millar. 2005. "Does the Minimum Wage Affect Welfare Caseloads?" Journal of Policy Analysis and Management 24 (2):273-295.

Pei, Z., J.-S. Pischke, and H. Schwandt. 2018. "Poorly Measured Confounders Are More Useful on the Left Than on the Right." Journal of Business \& Economic Statistics:1-12.

Pesko, M. F. 2014. "Stress and Smoking: Associations with Terrorism and Causal Impact." Contemporary Economic Policy 32 (2):351-371.

Pesko, M. F., and J. M. Currie. 2019. "E-Cigarette Minimum Legal Sale Age Laws and Traditional Cigarette Use among Rural Pregnant Teenagers." Journal of Health Economics.

Pesko, M. F., J. Huang, L. D. Johnston, and F. J. Chaloupka. 2018. "E-Cigarette Price Sensitivity among Middle-and High-School Students: Evidence from Monitoring the Future." Addiction 113 (5):896-906.

Pesko, M. F., J. M. Hughes, and F. S. Faisal. 2016. "The Influence of Electronic Cigarette Age Purchasing Restrictions on Adolescent Tobacco and Marijuana Use." Preventive Medicine 87:207-12.

Pesko, M. F., D. S. Kenkel, H. Wang, and J. M. Hughes. 2016. "The Effect of Potential Electronic Nicotine Delivery System Regulations on Nicotine Product Selection." Addiction 111 (4):734-44.

Pesko, M. F., and C. Warman. 2017. The Effect of Prices on Youth Cigarette and E-Cigarette Use: Economic Substitutes or Complements? In Social Science Research Network.

Remler, D. K. 2004. "Poor Smokers, Poor Quitters, and Cigarette Tax Regressivity." American Journal of Public Health 94 (2):225-229. 
Sabia, J. J., and T. T. Nguyen. 2018. "The Effect of Medical Marijuana Laws on Labor Market Outcomes." The Journal of Law and Economics 61 (3):361-396.

Saffer, H., D. Dench, D. Dave, and M. Grossman. 2018. E-Cigarettes and Adult Smoking. In National Bureau of Economic Research Working Paper. Cambridge, MA: National Bureau of Economic Research.

Sterba, K. R., V. Rabius, M. J. Carpenter, P. Villars, D. Wiatrek, and A. McAlister. 2011. "Dyadic Efficacy for Smoking Cessation: Preliminary Assessment of a New Instrument." Nicotine \& Tobacco Research 13 (3):194-201.

Stoklosa, M., J. Drope, and F. J. Chaloupka. 2016. "Prices and E-Cigarette Demand: Evidence from the European Union." Nicotine \& Tobacco Research 18 (10):1973-1980.

U.S. Department of Health and Human Services. 2016. E-Cigarette Use among Youth and Young Adults: A report of the Surgeon General. Rockville, MD: U.S. Department of Health and Human Services.

University of Kentucky Center for Poverty Research. 2019. Ukcpr National Welfare Data, 19802017. Lexington, KY: Gatto College of Business and Economics, University of Kentucky.

Vapor Products Tax. 2018. Tax Data Center.

Wang, T. W., K. Asman, A. S. Gentzke, K. A. Cullen, E. Holder-Hayes, C. Reyes-Guzman, A. Jamal, L. Neff, and B. A. King. 2018. "Tobacco Product Use among Adults-United States, 2017." Morbidity and Mortality Weekly Report 67 (44):1225.

Webber, D. A. 2016. "Are College Costs Worth It? How Ability, Major, and Debt Affect the Returns to Schooling." Economics of Education Review 53:296-310.

Winickoff, J. P., M. Gottlieb, and M. M. Mello. 2014. "Tobacco 21-an Idea Whose Time Has Come." New England Journal of Medicine 370 (4):295-297.

Zheng, Y., C. Zhen, D. Dench, and J. M. Nonnemaker. 2017. "U.S. Demand for Tobacco Products in a System Framework." Health Economics 26 (8):1067-1086. 